ARTICLE

Received 4 Aug 2016 | Accepted 31 Mar 2017 | Published 26 May 2017

DOI: $10.1038 /$ ncomms15480

OPEN

\title{
Design of live attenuated bacterial vaccines based on D-glutamate auxotrophy
}

\author{
Maria P. Cabral ${ }^{1, \star}$, Patricia García ${ }^{1, \star}$, Alejandro Beceiro ${ }^{1}$, Carlos Rumbo ${ }^{1}$, Astrid Pérez ${ }^{1}$, Miriam Moscoso ${ }^{1}$ \\ \& Germán Bou ${ }^{1}$
}

Vaccine development is a priority for global health due to the growing multidrug resistance in bacteria. D-glutamate synthesis is essential for bacterial cell wall formation. Here we present a strategy for generating effective bacterial whole-cell vaccines auxotrophic for D-glutamate. We apply this strategy to generate D-glutamate auxotrophic vaccines for three major pathogens, Acinetobacter baumannii, Pseudomonas aeruginosa and Staphylococcus aureus. These bacterial vaccines show virulence attenuation and self-limited growth in mice, and elicit functional and cross-reactive antibodies, and cellular immunity. These responses correlate with protection against acute lethal infection with other strains of the same species, including multidrug resistant, virulent and/or high-risk clones such as A. baumannii $\mathrm{AbH} 12 \mathrm{O}-\mathrm{A} 2$ and Ab307-0294, P. aeruginosa PA14, and community-acquired methicillin-resistant S. aureus USA300LAC. This approach can potentially be applied for the development of live-attenuated vaccines for virtually any other bacterial pathogens, and does not require the identification of virulence determinants, which are often pathogen-specific.

\footnotetext{
${ }^{1}$ Microbiology Department, University Hospital A Coruña (CHUAC)-Biomedical Research Institute A Coruña (INIBIC), 15006 A Coruña, Spain.

* These authors contributed equally to this work. Correspondence and requests for materials should be addressed to G.B.

(email: german.bou.arevalo@sergas.es).
} 
T he emergence of multidrug-resistant (MDR) bacteria such as MDR Acinetobacter baumannii, MDR Pseudomonas aeruginosa and methicillin-resistant-Staphylococcus aureus (MRSA), and the lack of licensed vaccines against these pathogens, have resulted in significantly increased mortality rates with limited or no options for therapeutic interventions ${ }^{1-5}$, although there are experimental vaccines in the preclinical pipeline for these pathogens ${ }^{6-8}$. Due to this threat to public health, a call for greater consideration for the role of vaccines and prevention to combat antibiotic-resistant bacteria was recently made by the National Vaccine Advisory Committee ${ }^{9}$. Bacterial live vaccines can be highly efficient because they are harmless versions of pathogenic bacteria and mimic the natural infection. They have been used extensively for decades to prevent respiratory or enteric pathogens in humans ${ }^{10-12}$, and the most frequent infections of herd animals ${ }^{13-20}$. Traditionally, attenuation of virulence was achieved through natural selection by multiple passages of the microorganism on growth medium, random mutagenesis or genetic modification of target genes to inducing virulence attenuation. Considering that there are no universal gene targets for bacterial attenuation, the latter approach usually involves basic knowledge of molecular mechanisms of pathogenicity for each bacterial species or strain.

D-glutamate (D-Glu) is an essential component of bacterial peptidoglycan and is found in the cell wall of virtually all bacteria $21-24$. Earlier work suggests that glutamate racemase (MurI; EC 5.1.1.3), enzyme that converts L-glutamate to D-Glu for the synthesis of peptidoglycan, can be targeted for antibiotic development ${ }^{25,26}$. However, none of the previous work proposed the usefulness of MurI mutants as live bacterial vaccines. In contrast, here we present a platform for the generation of effective live-attenuated bacterial vaccines composed of D-Glu auxotrophic strains, which can be obtained through the inactivation of the gene (or genes)-encoding MurI and also the gene (or genes) coding for the $\mathrm{D}$-amino acid transaminase (Dat) capable of catalysing the interconversion of D-alanine to D-Glu (Fig. 1). More importantly, this strategy has potential application to any bacterial pathogen.

In response to the challenge for combating antibiotic-resistant pathogens, we genetically manipulated these bacteria to obtain
D-Glu auxotrophic strains, creating mutant derivatives with in-frame deletions in MurI or MurI plus Dat-coding genes, on A. baumannii ATCC 17978, P. aeruginosa PAO1 and S. aureus 132 and demonstrated their reliable efficacy as live vaccines in a mouse model of acute lethal infection.

\section{Results}

Characterization of D-glutamate auxotrophic strains. Analysis of their genome sequences revealed two murI genes in A. baumannii strain ATCC 17978 (hereafter 'Ab') (A1S_0380/murI1 and A1S_3398/murI2 $)^{27}$, a single-murI gene in P. aeruginosa strain PAO1 (hereafter ' $\mathrm{Pa}$ ') (PA4662/murI) ${ }^{28}$ and a single-murI gene and a single-dat gene ${ }^{29}$ in S. aureus strain 132 (hereafter 'Sa'). All these genes were targeted for unmarked in-frame deletion. The resulting Pa $\Delta$ murI mutant showed an absolute requirement of exogenous D-Glu for growth. Likewise, the double-mutants Ab $\Delta$ murI1 $\Delta$ murI2 and Sa $\Delta$ murI $\Delta$ dat also required exogenous D-Glu for growth. However, the singlemutants grew normally without the addition of D-Glu (Fig. 2a). Using real-time PCR with quantitative reverse transcription (qRT-PCR) (Fig. 2b), we confirmed the absence of murI and dat genes mRNA in these mutant strains. This means that for those bacteria not possessing the Dat enzyme, the inactivation of a single- or multiple- MurI enzymes may be required for production of a D-Glu auxotrophic strain, as in the cases of $\mathrm{Pa}$ and $\mathrm{Ab}$ (MurI ${ }^{-}$mutants). In other cases, the inactivation of genes coding for MurI protein as well as those coding for Dat seems to be required (MurI ${ }^{-} \mathrm{Dat}^{-}$mutants), as in the case of Sa.

To assess the effects of D-Glu deprivation on cellular growth of the wild-type and D-Glu auxotrophic strains, we collected bacteria grown in media supplemented with different concentrations of D-Glu and performed a morphological analysis by scanning electron microscopy (SEM) (Fig. 2c). Ab $\Delta$ murI1 $\Delta m u r I 2, \mathrm{~Pa} \Delta m u r I$ and Sa $\Delta m u r I$ dat showed growth impairment when the exogenous supply of D-Glu decreased, until complete loss of replication. Both Ab $\Delta$ murI1 $\Delta$ murI2 and Sa $\Delta m u r I \Delta$ dat strains exhibited an altered pattern of cell division when D-Glu was supplied at $0.1 \mathrm{mM}$. The Ab $\Delta$ murI1 $\Delta$ murI2 mutant showed filamentous aggregates consisting of three or
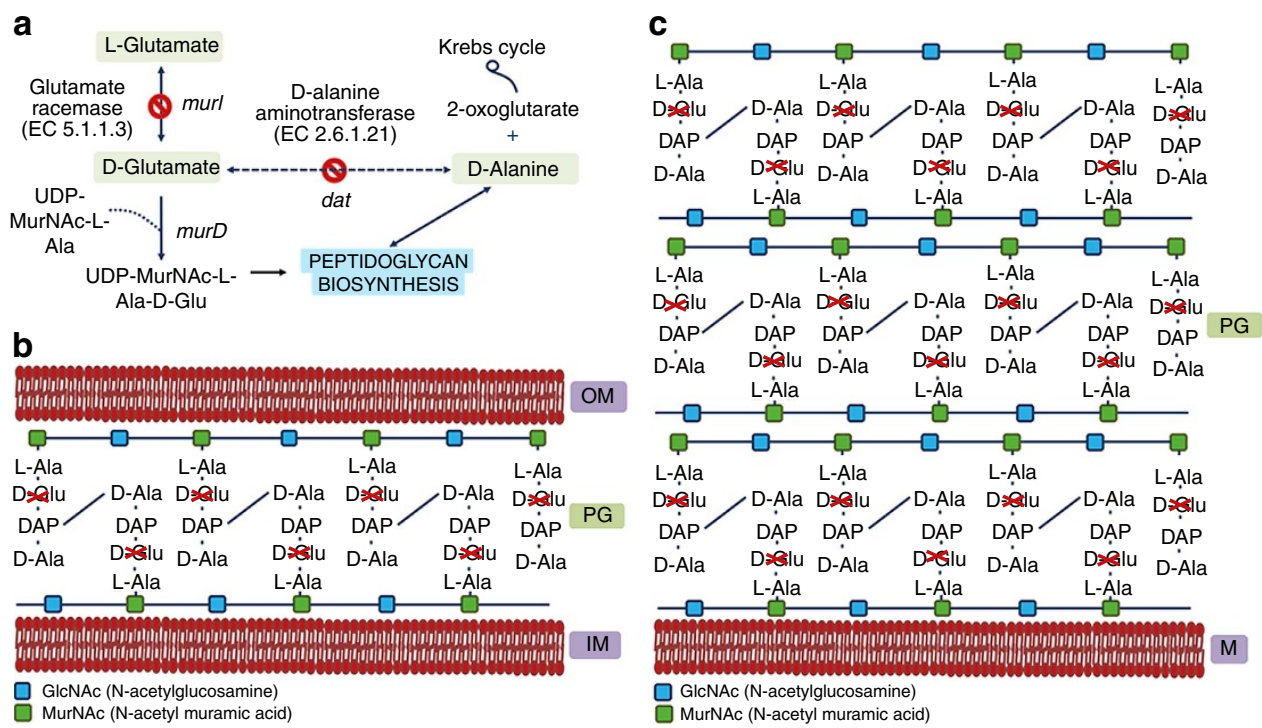

Figure 1 | D-Glu auxotrophy is achieved by inactivation of D-Glu producing enzymes. (a) Sequence of metabolic processes culminating in the formation of D-Glu and the incorporation in the bacterial peptidoglycan. (b) Cell wall structure of a gram-negative bacterium (non-depicted lipopolysaccharides and proteins). (c) Cell wall structure of a gram-positive bacterium (non-depicted teichoic acids and proteins). D-Ala, D-alanine; DAP, Diaminopimelic acid; D-Glu, D-glutamate; PG, peptidoglycan; OM, outer membrane; IM, inner membrane; M, cytoplasmic membrane. 
a
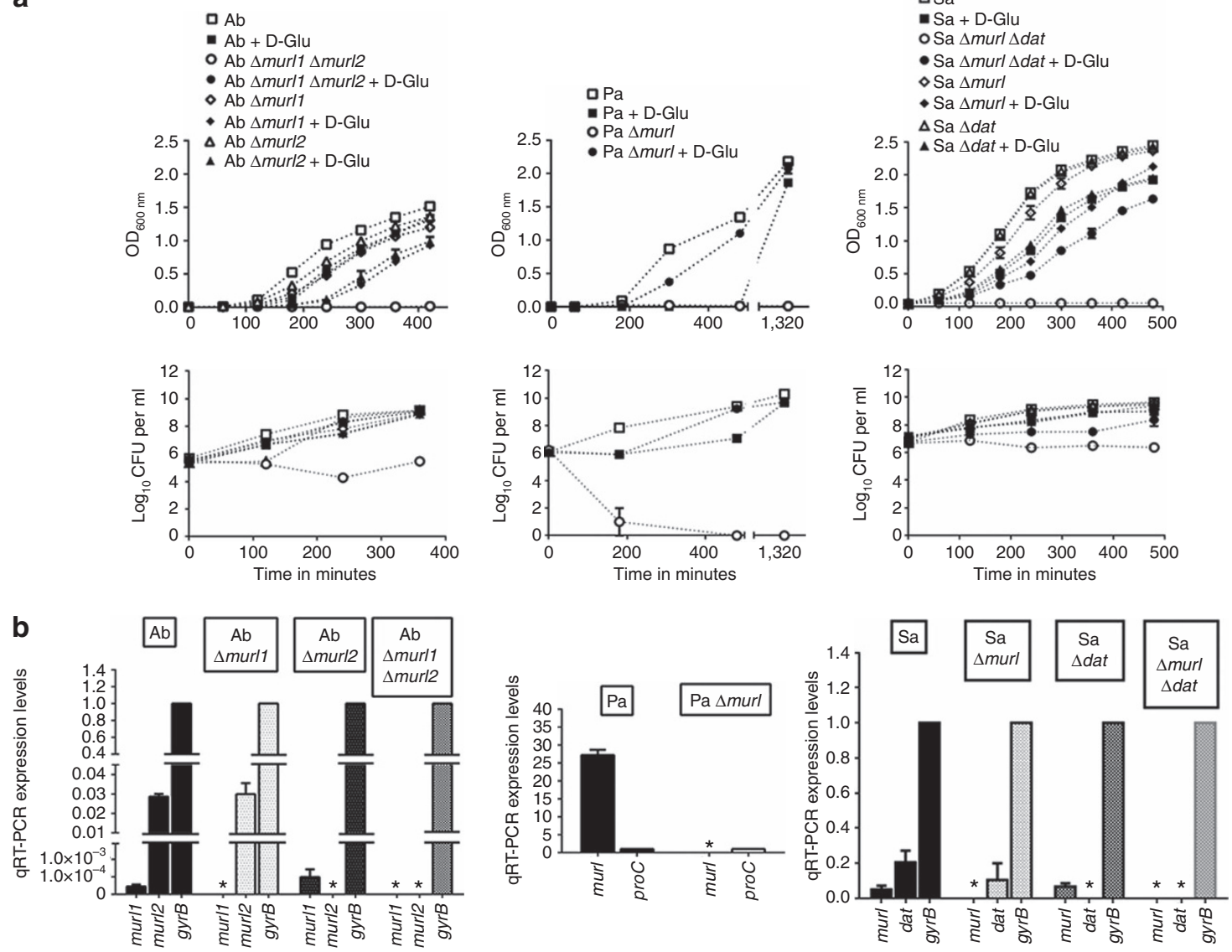

C
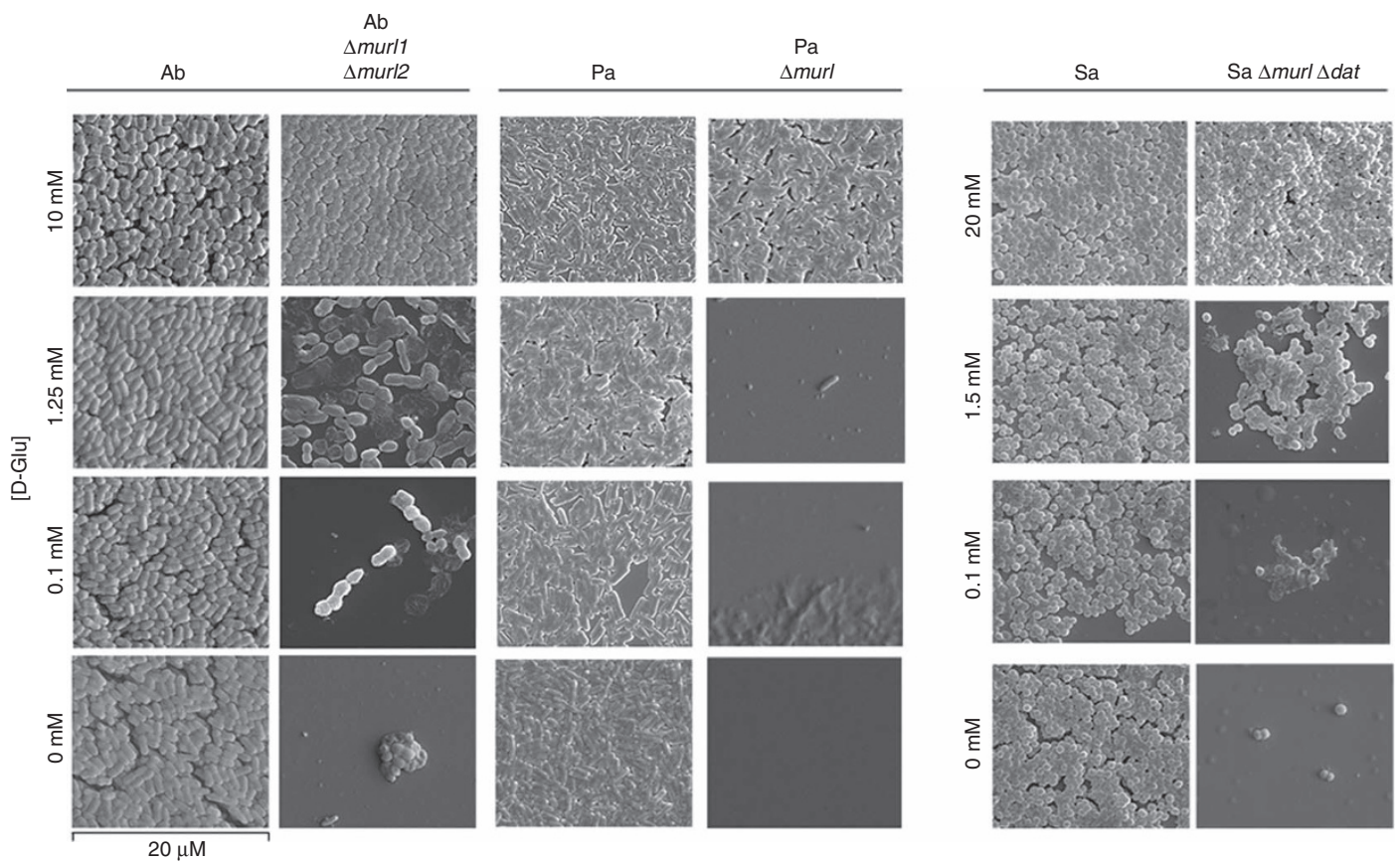

Figure 2 | Characterization of D-Glu auxotrophic. (a) Growth and viability of A. baumannii ATCC 17978 (Ab), P. aeruginosa PAO1 (Pa), S. aureus 132 (Sa) and derived mutant strains (mean \pm s.e.m.). (b) Comparative expression levels by qRT-PCR of murl in Ab (normalized relative to gyrB), murl in Pa (normalized relative to $\mathrm{proC}$ ), murl and dat in Sa (normalized relative to gyr $B$ ) and derived mutant strains (mean \pm s.d.). ${ }^{\star} P<0.05$. (c) $\mathrm{SEM}$ of $A b, P a, S a$ and derived D-Glu auxotrophic strains in the presence of different D-Glu concentrations.

more units of cells with atypical binary fission while Sa $\Delta$ murI $\Delta$ dat displayed large clusters of irregular cells due to impaired cell separation (Supplementary Fig. 1). A mass of presumptive protoplasts was observed in the vicinity of the intact cell forms of the mutant strains. With $1.25 \mathrm{mM}$ D-Glu for A. baumannii and $1.5 \mathrm{mM} \mathrm{D}$-Glu for S. aureus (Fig. 2c) a greater cell density was 
seen with respect to the preceding condition but with many visible protoplast-like structures. Also, though lower in number, some cells had an appearance similar to their wild-type morphology. Finally, when D-Glu was supplemented at 10 or $20 \mathrm{mM}$, both morphology and cell density of the mutant strains were indistinguishable from the corresponding wild-type homologues.

Transmission electron microscopy (TEM) showed that the cell walls of the three mutant strains experienced progressive destruction when kept in the absence of D-Glu. We observed cells with altered conformations that had lost their semi-rigid structure, several ruptures and displacement of membranes, lysis and extrusion of the intracellular content (Fig. 3). Thus, we propose the following mechanism for the lysis of D-Glu auxotrophic bacteria (Fig. 3d). First, blockage of peptidoglycan biosynthesis leaves the protoplasm surrounded only by the inner membrane (gram-negative) or cell membrane (gram-positive bacteria), which renders this cell body susceptible to the variations in the osmolarity of the medium. Ultimately, lysis occurs through osmotic pressure, leaving traces of the cytoplasmic membranes that can form aggregates, and internal cellular content. These phenomena may occur either simultaneously or sequentially.

To be safe and suitable as a genetically modified organism (GMO) vaccine, an inherent property of these organisms must be that the attenuation mutations are not reversible ${ }^{30}$. To check the irreversibility of the nutritional, the three mutant strains were grown with D-Glu and their viability evaluated for 8 days on agar plates with and without D-Glu. In the hypothetical case of a phenotype reversion, similar bacterial counts would be expected in plates over time. In contrast, we observed higher bacterial counts in supplemented plates at the initial stage of incubation and on subsequent days than on standard medium (Supplementary Fig. 2a), indicating that these strains remain auxotrophic for D-Glu over time. a
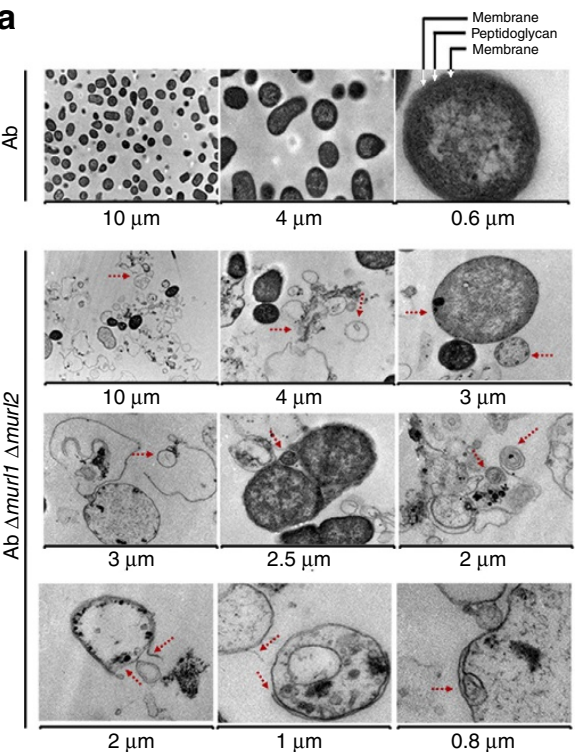

C

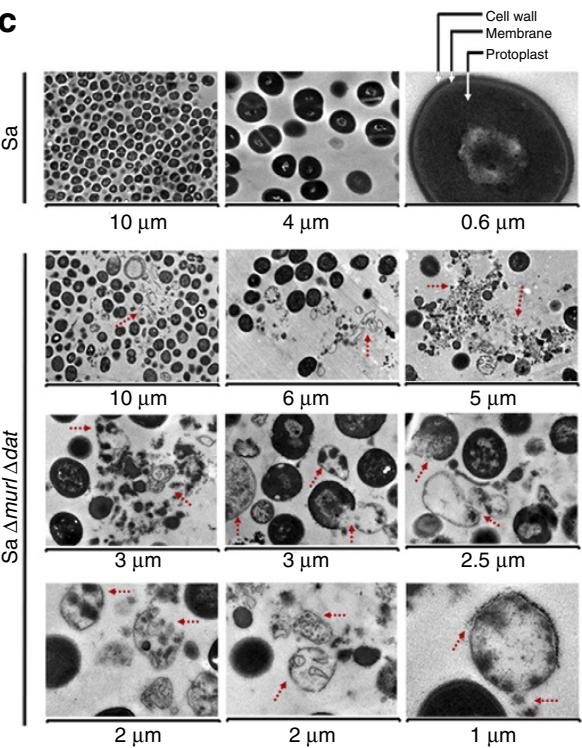

b
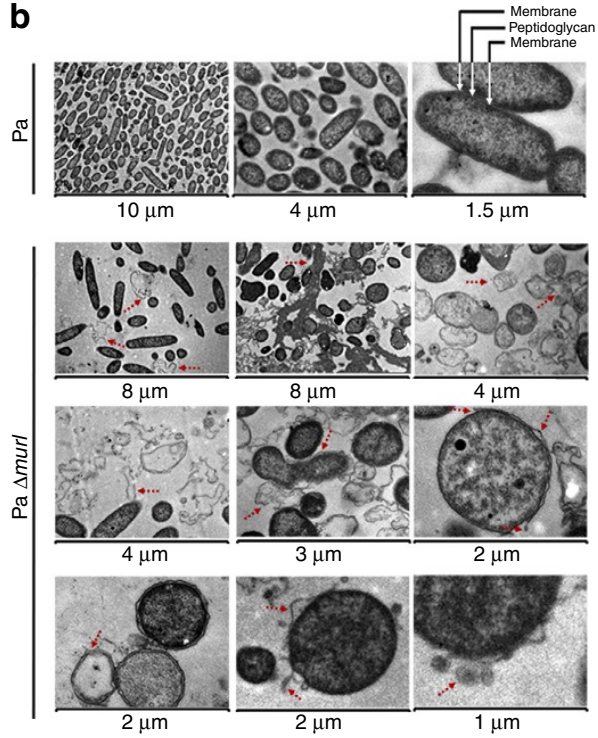

d

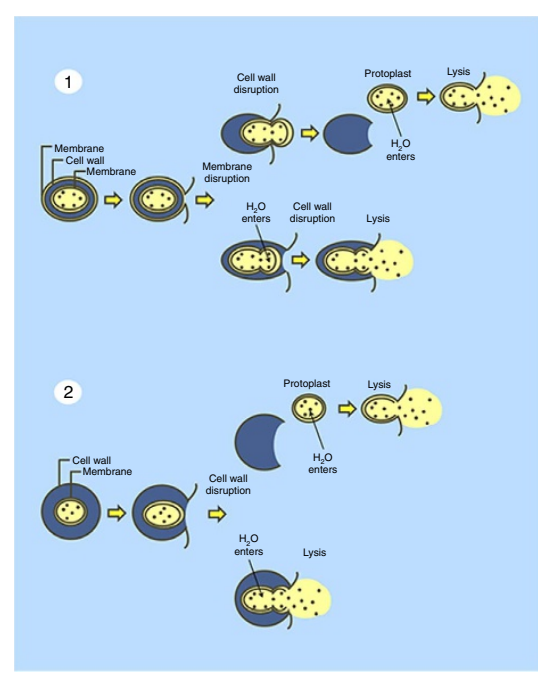

Figure 3 | D-Glu auxotrophy produces cell wall degeneration and bacterial lysis. (a-c) Different atypical morphologies, progressive degeneration of the cell wall, membrane-bursting events and lysis of D-Glu auxotrophic strains after being kept in the absence of D-Glu (red dotted arrows). Micrographs were taken with a TEM at different scales. (a) A. baumannii ATCC 17978 (Ab) and Ab $\Delta$ murl1 $\Delta$ murl2. (b) P. aeruginosa PAO1 (Pa) and Pa $\Delta$ murl. (c) S. aureus 132 (Sa) and Sa $\Delta$ murl $\Delta$ dat. (d) Proposed schematic mechanism of cell wall degeneration and bacterial lysis of (1) gram-negative and (2) gram-positive bacteria auxotrophic for D-Glu. 
Also, any live-attenuated bacterial strain constituting the active ingredient of a vaccine should be unable of replicating and persisting in the general environment if it hypothetically leaves the vaccinated individual ${ }^{30}$. Thus, persistence of D-Glu auxotrophic strains was compared with that of their wild-type homologues. We observed marked differences in the viability of $\mathrm{Ab} \Delta$ murI1 $\Delta$ murI2 and $\mathrm{Pa} \Delta m u r I$ with respect to their respective wild-type strains when analysing survival in water (Supplementary Fig. 2b). For S. aureus, a progressive reduction in the viability of Sa $\Delta m u r I \Delta d a t$ but not of the parental strain was observed using a desiccation model (Supplementary Fig. 2c).

Virulence attenuation of $\mathrm{MurI}^{-}$and $\mathrm{MurI}^{-} \mathrm{Dat}^{-}$mutants. One of the main characteristics that makes GMOs especially suitable for use as vaccines is the higher level of virulence attenua$\operatorname{tion}^{30}$. To test the hypothesis that bacteria auxotrophic for D-Glu are attenuated, we measured mice survival after intraperitoneal (IP) injection with these strains (Supplementary Fig. 3). Using this model of acute systemic infection, the $\mathrm{LD}_{100}$ (the minimal lethal dose for $100 \%$ of mice) of wild-type homologues were $1.5 \times 10^{8}$ $\mathrm{CFU}$ for $\mathrm{Ab}, 2 \times 10^{7} \mathrm{CFU}$ for $\mathrm{Pa}$ and $7 \times 10^{7} \mathrm{CFU}$ (with $3 \%$ of mucin) for Sa. In contrast, the observed $\mathrm{LD}_{100}$ for the three mutant strains were $6 \times 10^{8} \mathrm{CFU},>2 \times 10^{9} \mathrm{CFU}$ and $>3.5 \times 10^{8} \mathrm{CFU}$ (with $3 \%$ of mucin), respectively.

Generation of antibody-mediated immune responses. To measure the antibody-mediated immune responses at different vaccination regimens, $\mathrm{BALB} / \mathrm{c}$ mice were immunized with $\mathrm{D}-\mathrm{Glu}$ auxotrophic strains (systematically by IP administration of $\sim 6 \times 10^{7} \mathrm{CFU}$ for $\mathrm{Ab} \Delta$ murI1 $\Delta$ murI2, $2 \times 10^{7} \mathrm{CFU}$ for $\mathrm{Pa}$ $\Delta m u r I$ and $3 \times 10^{7} \mathrm{CFU}$ for Sa $\Delta$ murI $\Delta$ dat; hereafter ' $\alpha-\mathrm{Ab}$ ', ' $\alpha$ $\mathrm{Pa}$ ' and ' $\alpha$-Sa' vaccines, respectively) or administered saline according to Fig. 4a, and antibody titres were determined by enzyme-linked immunosorbent assay (ELISA). Significant levels of IgM, IgG, IgG1, IgG2a, IgG2b and IgG3 against A. baumannii ATCC 17978, $P$. aeruginosa PAO1 and protein A-deficient $S$. aureus $132(132 \Delta s p a)^{29}$ were present in all immunized mice on days $21-25(P<0.05$, Student's $t$-test). Antibody production after two immunizations was considerably higher than with one immunization $(P<0.05$, one-way analysis of variance (ANOVA) followed by Bonferroni's post hoc test), and titres generally persisted without booster vaccinations until days 292-301, that is, almost 10.5 months after the last immunization. Long-term specific antibody responses were also observed by immunization with different doses of $\alpha$-Sa vaccine (Supplementary Fig. 4). Analysis of the IgG isotype revealed that vaccination with any of the D-Glu auxotrophic strains triggered a dominant IgG1 response, consistent with a predominant activation of Th2 lymphocytes $^{31}$. Despite IgG2a and IgG2b levels being substantially lower in the short-time response to $\alpha$-Sa vaccine, titres were still significant $(P<0.05$, Student's $t$-test) in vaccinated groups and showed a progressive increase after day 21 . These results indicate that a Th1 differentiation was also stimulated upon vaccination ${ }^{31}$. By using the intramuscular route, significant levels of antibodies as well as prevailing IgG1 subtype were also elicited after three immunizations with $\alpha$-Pa vaccine (days 35-40), as shown in Fig. 4b.

While $\mathrm{BALB} / \mathrm{c}$ have a Th2-dominant immune response, C57BL/6 mice are prone to response bias Th1 (ref. 31). To rule out any confounding effect of the immune system inherent to the inbred mouse strain, we vaccinated C57BL/6 mice with D-Glu auxotrophic strains. Similar to $\mathrm{BALB} / \mathrm{c}$ mice, we observed substantial antibody production after completion of the immunization schedules (Supplementary Fig. 5).
We also evaluated immune responses in $\mathrm{BALB} / \mathrm{c}$ mice administered different doses of the three mutant strains (Supplementary Fig. 6). Significant levels of IgM and total IgG were present in all immunized mice at the end of the immunization schedules $(P<0.05$, Student's $t$-test $)$. All tested $\alpha$-Ab vaccine doses above $\sim 2 \times 10^{6}$ CFU elicited significant levels of IgG1, IgG2a, IgG2b and IgG3 subtypes. Although $6 \times 10^{6}$ $\mathrm{CFU}$ of $\alpha$-Pa vaccine was sufficient to induce IgM and IgG titres substantially, total IgG titres were higher when using a dose of $2 \times 10^{7}$ CFU. For $\alpha$-Sa vaccine, only doses of $7.5 \times 10^{7}$ and $1.5 \times 10^{8} \mathrm{CFU}$ raised significantly all IgG subtypes $(P<0.05$, Student's $t$-test); while using $2.5 \times 10^{7} \mathrm{CFU}$ elicited IgG1 and IgG3 subtypes only.

Adverse reactions can potentially occur upon vaccine administration. In those cases, vaccines need to be reformulated without their immunogenic properties being negatively affected. To test the ability of D-Glu auxotrophic vaccines to trigger humoral responses at low-dose formulation, a single immunization with $4 \times 10^{3} \mathrm{CFU}$ of $\alpha$-Ab vaccine was used in BALB/c mice (Fig. $4 \mathrm{c}$ ). Despite the low dose used, significant levels of antigen-specific $\operatorname{IgM}, \operatorname{IgG}, \operatorname{IgG} 1, \operatorname{IgG} 2 \mathrm{a}, \operatorname{IgG} 2 \mathrm{~b}$ and IgG3 were detected in the sera of mice ( $P<0.05$, Student's $t$-test), 123 days and 1 year after the immunization. Also, IgM titres were higher at day 7 but markedly reduced on day 123. In contrast, IgG1, IgG2b and IgG3 titres increased significantly between days 7 and $123(P<0.05$, one-way ANOVA followed by Bonferroni's post hoc test); total IgG levels were maintained until 1 year after immunization, indicating a biphasic response and long-term antibody memory.

A key feature of any single-strain vaccine is its ability to generate antibodies reactive against heterologous strains. IgG antibodies elicited with $\alpha$-Ab vaccine and obtained on days 21 , 42, 98 and 293 were cross-reactive with A. baumannii ATCC 19606, MDR-AbH12O-A2 and encapsulated-Ab307-0294 strains (Fig. 4d). IgG antibodies obtained on days 21-25 after two $\alpha$-Pa immunizations were cross-reactive with $P$. aeruginosa PA21_ST175, PA14, PA51441321, PA12142, LES400, LES431, PA28562 and PA51442390. At days 42, 98 and 292, these IgG's were cross-reactive with the previous strains plus $P$. aeruginosa PA_ST235. Also, IgG's obtained with three $\alpha$-Pa immunizations were cross-reactive against all the $P$. aeruginosa strains tested (Supplementary Fig. 7). Of note, $P$. aeruginosa PA28562 and PA51442390 present the mucoid phenotype associated with chronic infections from cystic fibrosis patients ${ }^{32}$. IgG antibodies elicited with $\alpha$-Sa vaccine and obtained on days 21, 42, 98 and 301 were cross-reactive with S. aureus FPR3757 and MW2 strains of the clinically relevant CA-MRSA high-risk clones USA300 and USA400, respectively; with NEWMAN and Sa07997; as well as with S. aureus strains of animal origin, RF122 (bovine), ED133 (ovine) and ED98 (poultry). These data indicate that vaccination with D-Glu auxotrophic strains elicits both early and long-term antibody memory against parental and heterologous unrelated strains, suggesting these vaccine candidates would be suitable to induce ample protection.

In addition, vaccination with $\alpha$-Sa strain elicited IgG crossreactivity with a variety of coagulase-negative $(\mathrm{CoN})$ Staphylococci species (Supplementary Fig. 8), supporting that $\alpha$-Sa vaccine could be considered for broader applications, such as the prevention of device-associated health care-associated infections recognized as the most clinical relevant CoN-staphylococcal infections.

Activation of cell-mediated immunity. To explore the nature of T-cell responses generated by the vaccine strains, we measured antigen-specific IFN- $\gamma$-, IL-4- and IL-17-secreting splenocytes of $\mathrm{BALB} / \mathrm{c}$ mice after ex vivo restimulation, using ELISpot. These 
a
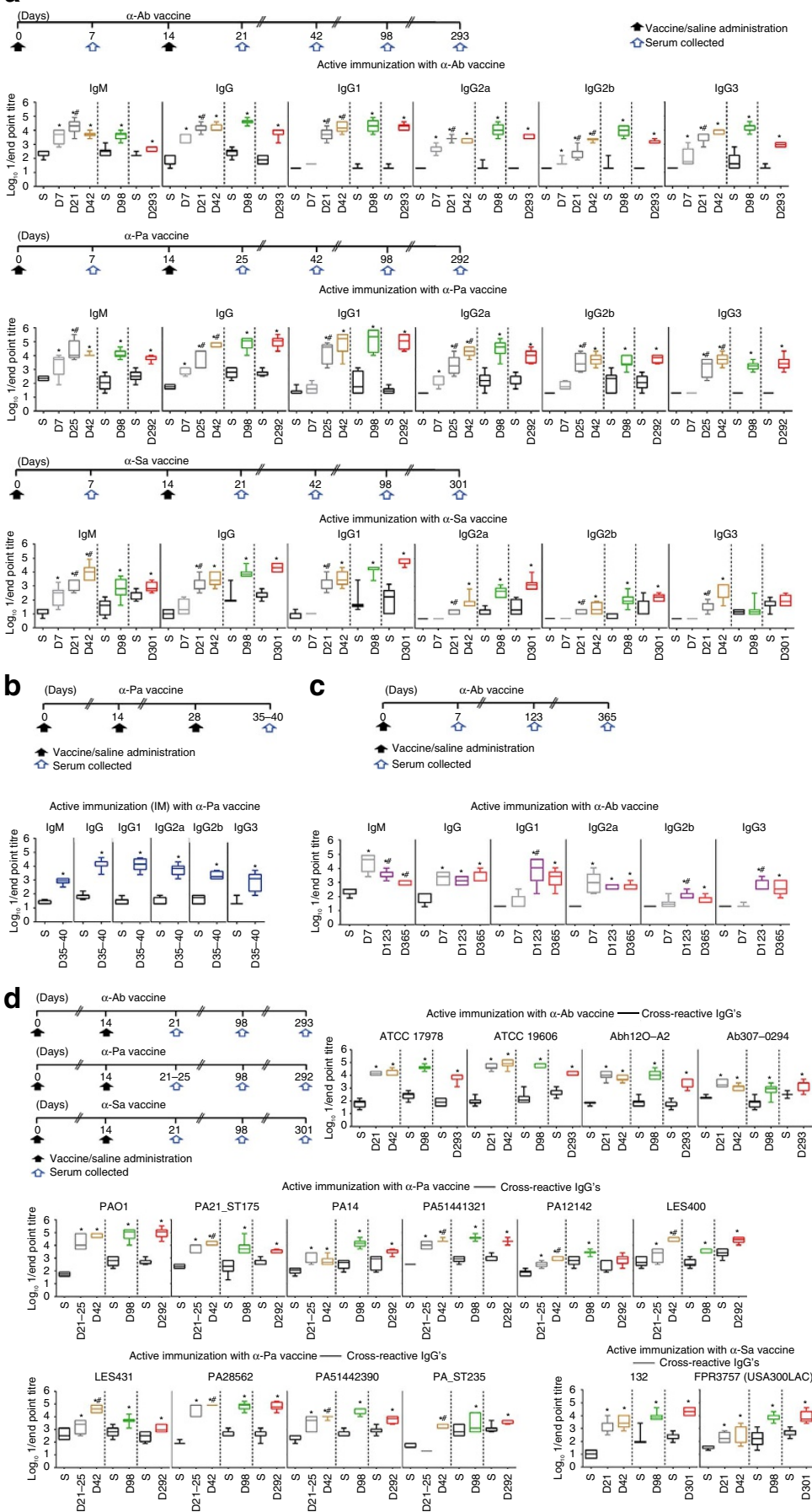

Active immunization with $\alpha$-Sa vac
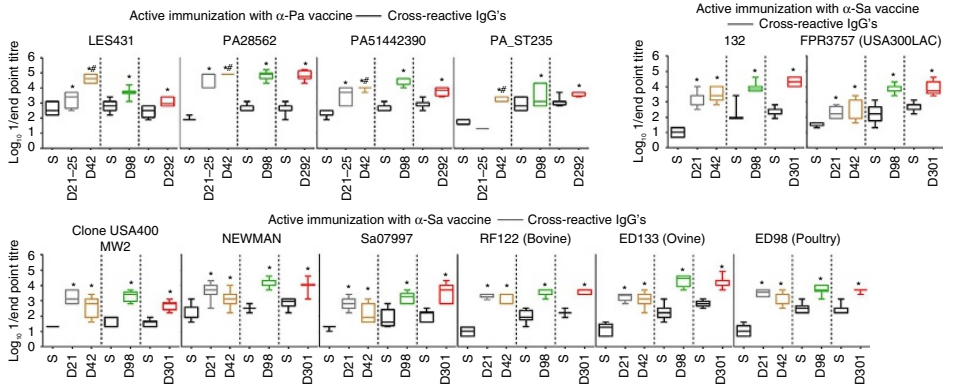

Figure 4 | Vaccination with D-Glu auxotrophic strains elicits early and long-term antibody memory against parental and heterologous unrelated strains.. (a) Antibody titres against A. baumannii ATCC $17978(n=5-13)$, P. aeruginosa PAO1 $(n=4-10)$ and S. aureus $132 \Delta$ spa $(n=5-10)$ in vaccinated and control mice after one or two injections with ATCC $17978 \Delta$ murl1 $\Delta$ murl2 ( $\alpha$-Ab vaccine) $\left(6 \times 10^{7}\right.$ CFU), PAO1 $\Delta$ murl $(\alpha-P a$ vaccine $)\left(2 \times 10^{7}\right.$ CFU) and $132 \Delta$ murl $\Delta$ dat ( $\alpha$-Sa vaccine) $\left(3 \times 10^{7} \mathrm{CFU}\right)$, respectively, or saline. (b) Antibody titres against PAO1 in vaccinated and control mice $(n=8)$ after three intramuscular (IM) injections with $\alpha$-Pa vaccine $\left(2 \times 10^{7} \mathrm{CFU}\right)$, or saline, respectively. (c) Antibody titres against ATCC 17978 in vaccinated and control mice $(n=5-8)$ after $\alpha$-Ab vaccine $\left(4 \times 10^{3} \mathrm{CFU}\right)$, or saline administration, respectively. (d) IgG titres against different $A$. baumannii $(n=6-10), P$. aeruginosa $(n=5-10)$ and S. aureus $(n=7-10)$ strains in vaccinated and control mice after two injections with $\alpha$-Ab $\left(6 \times 10^{7} \mathrm{CFU}\right), \alpha$-Pa $\left(2 \times 10^{7} \mathrm{CFU}\right)$ and $\alpha$-Sa $\left(3 \times 10^{7} \mathrm{CFU}\right)$ vaccines, respectively, or saline. (a-d) S, saline; D, day. ${ }^{\star} P<0.05$ (Student's $t$-test), compared with saline group. $\# P<0.05$, compared with the preceding condition (one-way ANOVA followed by Bonferroni's post hoc test). 


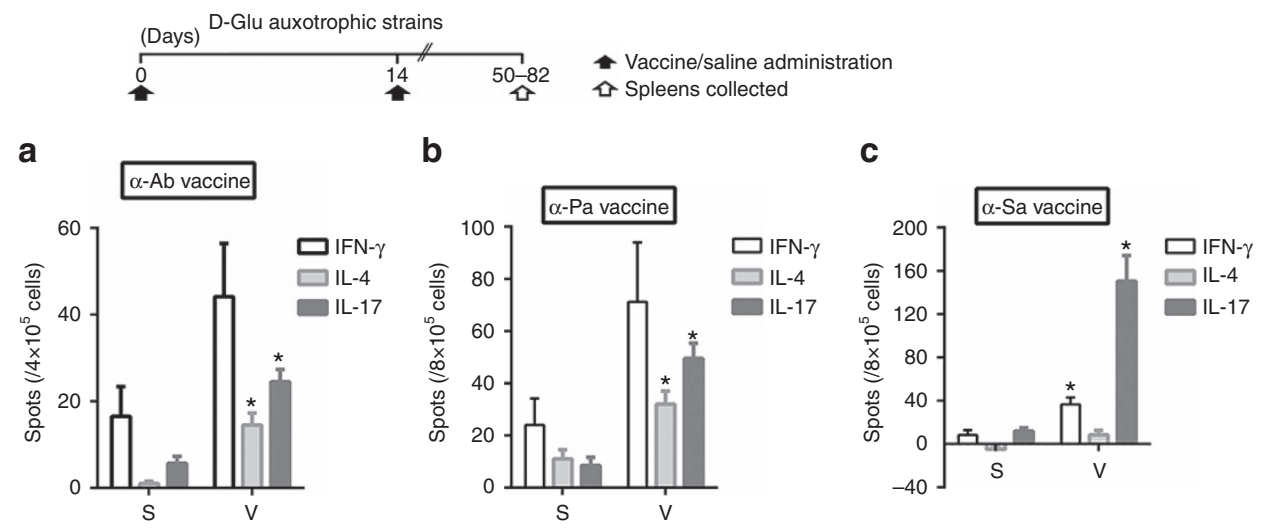

Figure 5 | Vaccination with D-Glu auxotrophic strains triggers cytokine-secreting T-cells. (a) Number of spot-forming cells per $4 \times 10^{5}$ splenocytes collected at day 82 from mice vaccinated twice with A. baumannii ATCC $17978 \Delta$ murl1 $\Delta$ murl2 ( $\alpha$-Ab vaccine) $\left(6 \times 10^{7}\right.$ CFU) $(n=6)$ and control mice $(n=7)$ after being restimulated ex vivo with $\alpha$-Ab vaccine $\left(4 \times 10^{5}\right.$ CFU). (b) Number of spot-forming cells per $8 \times 10^{5}$ splenocytes collected at day 68 from mice vaccinated twice with P. aeruginosa PAO1 $\Delta$ murl ( $\alpha$-Pa strain) $\left(2 \times 10^{7}\right.$ CFU) $(n=6)$ and control mice $(n=6)$ after being restimulated ex vivo with $\alpha$-Pa vaccine $\left(8 \times 10^{4} \mathrm{CFU}\right)$. (c) Number of spot-forming cells per $8 \times 10^{5}$ splenocytes collected at day 50 from mice vaccinated twice with $S$. aureus 132 $\Delta$ murl $\Delta$ dat $\left(\alpha\right.$-Sa vaccine) $\left(3 \times 10^{7} \mathrm{CFU}\right)(n=6)$ and control mice $(n=6)$ after being restimulated ex vivo with $\alpha$-Sa vaccine $\left(3 \times 10^{6} \mathrm{CFU}\right)$. (a-c) S, saline; $\checkmark$, vaccinated. ${ }^{\star} P<0.05$ (Student's $t$-test), compared with saline control mice (mean \pm s.e.m.).

cytokines were selected as markers of Th1, Th2 and Th17 T-cell subsets, respectively. All three mutant strains induced an increase in the number of IL-17-secreting splenocytes, and this was the predominant T-cell subset triggered by the $\alpha$-Sa vaccine (Fig. 5). A significant number of IFN- $\gamma$-secreting splenocytes was stimulated by $\alpha$-Sa vaccine $(P<0.05$, Student's $t$-test $)$, while an increment-although not statistically significant-was observed with $\alpha-\mathrm{Ab}$ and $\alpha$-Pa vaccines. IL-4-producing splenocytes were stimulated in response to $\alpha$-Ab and $\alpha$-Pa strains, but not to $\alpha$-Sa vaccine. These data indicate that active immunization with $\alpha-\mathrm{Ab}$ and $\alpha$-Pa vaccines triggers a consistent Th2 immune response while $\alpha$-Sa vaccine elicits a Th1 response.

Protective immunity against acute infection. Antibody and cellmediated immunity can only be predictors for protective immune responses. To verify whether D-Glu auxotrophic strains confer protection, we assessed their effectiveness using an acute systemic infection model in mice (Figs 6-8). First, the effect of vaccination was determined by measuring bacterial loads in multiple tissues from vaccinated and control mice after injection with the vaccine wild-type homologues. Vaccination with D-Glu auxotrophic strains resulted in all cases in a significant reduction in tissue bacterial loads $\left(10^{4}-10^{6}\right.$-fold reductions, $P<0.05$, MannWhitney $U$ test) compared to those observed in control mice (Figs 6a,7a and 8a). Moreover, the $\alpha$-Sa vaccine prevented mice from severe body weight loss. Further, we determined mice survival after challenge with parental and heterologous strains. A two-dose vaccination schedule with the $\alpha$-Ab strain protected mice from challenge with the wild-type strain $A$. baumannii ATCC 17978 on day 21, whereas all control mice died within $24 \mathrm{~h}$ (Fig. 6b). Similarly, survival rates of vaccinated mice were 100 and $86 \%$ after challenge with $A$. baumannii AbH12O-A2 on day 21, and Ab307-0294 on day 22, respectively. Mice challenged with $P$. aeruginosa PAO1 on day 25 presented 87.5 and $100 \%$ survival after vaccination with $2 \times 10^{6} \mathrm{CFU}$ and $2 \times 10^{7} \mathrm{CFU}$ of $\alpha$-Pa vaccine, respectively. In this case, all control mice died within $15 \mathrm{~h}$ (Fig. 7b). Similar results were obtained when challenging mice with the mucoid strain $P$. aeruginosa PA28562. Using the intramuscular route (Fig. $7 \mathrm{c}$ ), vaccinated mice challenged with PAO1 were also completely protected. Similar results were obtained for the highly virulent strain PA14: all vaccinated mice survived whereas $71 \%$ of control mice died. Using the IN route (Fig. $7 \mathrm{c}$ ), vaccinated mice challenged with PAO1 on day 49 presented $88.9 \%$ survival whereas all control mice died. Mice vaccinated with $3 \times 10^{7} \mathrm{CFU}$ of $\alpha$-Sa vaccine were completely protected from challenge with strain $S$. aureus 132 on day 21 , whereas $81.3 \%$ of control mice died within 11 days (Fig. 8b). All vaccinated mice recovered their pre-infection body weight within $85 \mathrm{~h}$. In addition, control mice that survived until day $53(n=3)$ presented high post-challenge bacterial loads in tissues $(4.33,6.66$ and 6.96 $\log _{10}$ CFU g ${ }^{-1}$ in livers; 0, 6.71 and $7.41 \log _{10}$ CFU g $^{-1}$ in the left kidneys) in contrast to vaccinated mice $\left(0 \log _{10} \mathrm{CFUg}{ }^{-1}\right.$ in liver and left kidneys; $n=3$, randomly selected). Moreover, multiple infectious abscesses were evident on the tissues of controls; but not detected on vaccinated mice (Fig. 8b). When challenging mice on day 21 with $S$. aureus FRP3757-USA300LAC, RF122 and ED98 strains, we observed 100\% survival, whereas all control mice died within $15 \mathrm{~h}$ (Fig. 8c). All these vaccinated mice recovered their initial body weight. We next assessed the protective efficacy of D-Glu auxotrophs in C57BL/6 mice. When challenged with the wild-type strains (ATCC 17978, PAO1 or 132), survival rates were $100 \%$ for vaccinated versus $0 \%$ for control mice (Figs $6 \mathrm{~b}, 7 \mathrm{~b}$ and $8 \mathrm{c}$ ); and when $\alpha-\mathrm{Pa}$ vaccine was administered intramuscular, survival was $100 \%$ for vaccinated versus $25 \%$ for control mice, after PAO1 infection (Fig. 7c).

To demonstrate mid- and long-term vaccine efficacy, challenges with parental and heterologous strains were carried out one and three months after the last immunization (days 42-43 and 98, respectively). As illustrated (Figs 6c,7c,d and $8 \mathrm{~d}, \mathrm{e}$ ), survival rates were higher than $88.9 \%$ in all vaccinated groups; and in case of $S$. aureus, $\alpha$-Sa-vaccinated mice began to recover their pre-infection body weight $30 \mathrm{~h}$ after the challenge (Fig. 8d,e). Conversely, all control mice infected with A. baumannii ATCC 17978, ATCC 19606 or AbH12O-A2 (Fig. 6c), or P. aeruginosa PAO1 or PA14 (Fig. 7d) died within $14 \mathrm{~h}$, whereas $90 \%, 89 \%$ and $55 \%$ mortality rates were observed after challenge with $S$. aureus 132, Sa07997 and FRP3757USA300LAC respectively (Fig. 8d,e). In addition, control mice that overcame the acute phase of $S$. aureus FRP3757-USA300LAC infection $(n=4)$ presented high bacterial loads in tissues on day $146\left(0,2.57,3.19\right.$ and $1.24 \log _{10}$ CFU g ${ }^{-1}$ in livers; 7.61, 7.85, 7.12 and $6.29 \log _{10} \mathrm{CFU} \mathrm{g}^{-1}$ in the left kidneys; 0, 3.23, 3.78 and $7.26 \log _{10} \mathrm{CFU} \mathrm{g}^{-1}$ in heart) in contrast to vaccinated mice $(0$ $\log _{10}$ CFU g $g^{-1}$ in liver, left kidneys and heart, $n=5$ randomly 
a
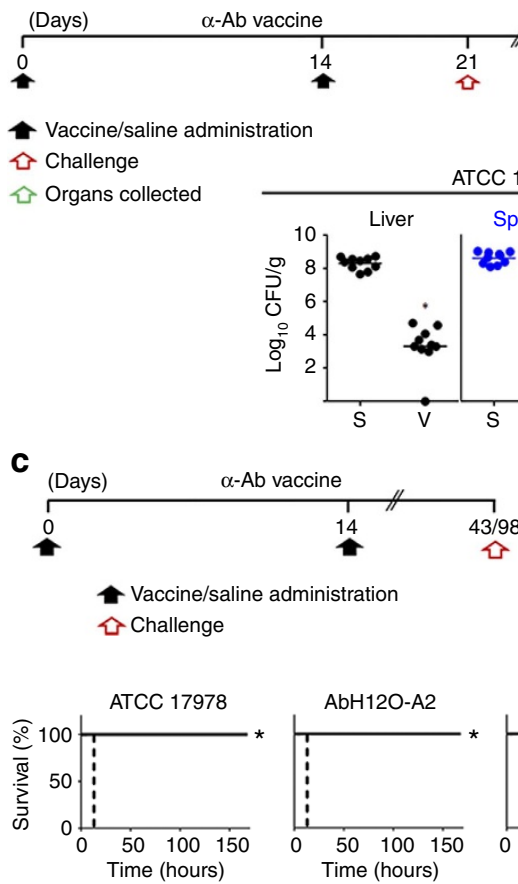

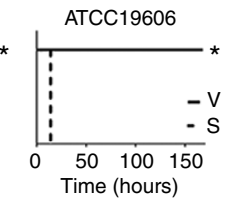

b

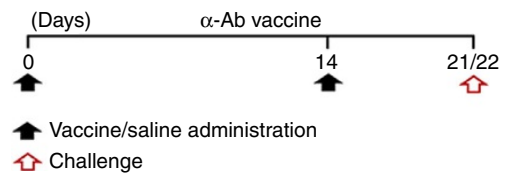

૫ Challenge
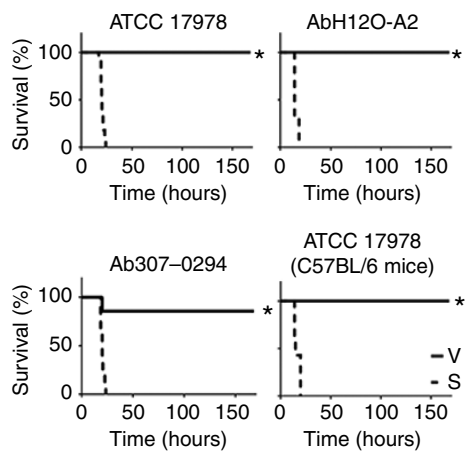

Figure 6 | Immunization with A. baumannii D-Glu auxotroph ( $\boldsymbol{\alpha}$-Ab vaccine) provides effective protection against diverse bacteria. (a) Protective effect against bacterial dissemination after acute infection. Bacterial loads in tissues from vaccinated $\left(6 \times 10^{7} \mathrm{CFU}\right.$ of $\alpha$-Ab strain) and control mice after challenge with A. baumannii ATCC $17978\left(3 \times 10^{8} \mathrm{CFU}\right)(n=10$; after $12 \mathrm{~h}) .{ }^{\star} P<0.05$ (Mann-Whitney U-test). (b) Early vaccine protection against infection. Mice survival after $\alpha$-Ab vaccine $\left(6 \times 10^{7}\right.$ CFU) or saline administration, and challenge with ATCC 17978 on day 21 ( $3 \times 10^{8}$ CFU, $n=11-13$ for $\mathrm{BALB} / \mathrm{C}$; and $6 \times 10^{8} \mathrm{CFU}, n=8$ for C57BL/6 mice), AbH120-A2 $\left(4 \times 10^{7} \mathrm{CFU}\right)$ on day $21(n=9)$ and Ab307-0294 (6 $\left.\times 10^{6} \mathrm{CFU}\right)$ on day $22(n=7-8)$. (c) Long-term vaccine protection against infection. Mice survival after $\alpha$-Ab vaccine $\left(6 \times 10^{7} \mathrm{CFU}\right)$ or saline administration, and challenge with ATCC $17978\left(3 \times 10^{8} \mathrm{CFU}\right)$ on day $98(n=10)$, AbH120-A2 ( $\left.4 \times 10^{7} \mathrm{CFU}\right)$ on day $98(n=10)$ and ATCC $19606\left(1 \times 10^{8} \mathrm{CFU}\right)$ on day $43(n=8)$. (a-c) S, saline; $\mathrm{V}$, vaccinated. $(\mathbf{b}, \mathbf{c}){ }^{\star} P<0.05$ (log-rank test), compared with saline group.

selected). Again, multiple infectious abscesses were evident in the tissues of controls (kidneys mainly), but not detected on vaccinated mice (Fig. 8e). Overall, these results demonstrate that vaccination with the $\mathrm{D}$-Glu auxotrophic strains provides midand long-term protection against systemic infections.

To address whether D-Glu auxotrophic strains have any benefit as vaccines over inactivated bacteria, we compared their effectiveness with heat-killed and formalin-inactivated wild-type strains, using the previous systemic infection model in mice (Figs 7e and 8f). A conventional two-dose vaccination schedule with $\alpha-\mathrm{Pa}$ vaccine protected mice from challenge with PA14, whereas all control mice died within $26 \mathrm{~h}$. In contrast, $55.6 \%$ of mice administered formalin-inactivated PAO1 succumbed to infection (Fig. 7e). Thus, $\alpha$-Pa vaccine conferred a statistically significant protection $(P<0.05$, log-rank test $)$ when compared with formalin-inactivated PAO1. Using a suboptimal schedule for immunization consisting of a sole dose of $\alpha$-Pa vaccine, formalininactivated PAO1 and heat-killed PAO1, we observed 100, 87.5 and $50 \%$ mice survival, respectively, after homologous challenge with PAO1. All control mice died within $14 \mathrm{~h}$. In this case, $\alpha-\mathrm{Pa}$ vaccine conferred protection when compared with heat-killed PAO1 (Fig. 7e). Survival rates for mice administered a unique dose of $\alpha$-Sa vaccine, formalin-inactivated 132 strain and heatkilled 132 strain were 50, 28.5 and $0 \%$, respectively, after challenge with FRP3757-USA300LAC; whereas all control mice died after infection (Fig. 8f). In this case, only mice administered $\alpha$-Sa vaccine were protected significantly against the heterologous challenge $(P<0.05$, log-rank test $)$.

Thus, D-Glu auxotrophic strains tested here conferred superior efficacy against acute infection when compared with inactivated wild-type bacteria.
Functional and protective vaccine antisera. In high-risk situations, the use of passive immunization may be beneficial. Those antibodies formed with $\alpha-\mathrm{Ab}, \alpha-\mathrm{Pa}$ and $\alpha$-Sa strains $(\alpha-\mathrm{Ab}, \alpha-\mathrm{Pa}$ and $\alpha$-Sa sera) can be obtained from the host and transferred into another recipient where they can provide immediate passive immunity. Since antibodies measured by ELISA often do not correlate with protection, we assessed the functionality of $\alpha-\mathrm{Ab}, \alpha-\mathrm{Pa}$ and $\alpha$-Sa sera by in vitro opsonophagocytic and killing activity (OPA/OPKA) assays, since these are generally more predictive. As illustrated in Fig. 9a, there was effective killing of $\alpha$-Ab serum in the presence of murine macrophages against A. baumannii ATCC 17978, ATCC 19606, AbH12O-A2 and Ab307-0294 strains, whether minimal killing was observed with naive serum. In the absence of macrophages, $\alpha$-Ab serum presented direct bactericidal activity against ATCC 17978, ATCC 19606 and AbH12O-A2 strains. There was effective killing of $\alpha$-Pa serum in the presence of human PMNs against $P$. aeruginosa PAO1, PA21_ST175, PA14 and PA28562 strains, whether minimal killing was observed with naive serum. In the absence of cells, $\alpha$-Pa serum also presented direct bactericidal activity against PAO1, PA21_ST175 and PA14 strains. Finally, significant opsonophagocytic activity of $\alpha$-Sa serum was observed against $S$. aureus 132, FRP3757-USA300LAC, MW2, NEWMAN, Sa07997, ED133 and ED98 strains, compared to naive serum in the presence of murine macrophages $(P<0.05$, Student's $t$-test). However, no bactericidal effect was detected in the absence of phagocytic cells.

Even though the generation of functional antibodies may be necessary to induce protective immunity, it could not be sufficient for complete protection against infection by certain pathogens and/or strains. In this sense, we determined if vaccine antisera formed with the D-Glu auxotrophs could be used to 
a

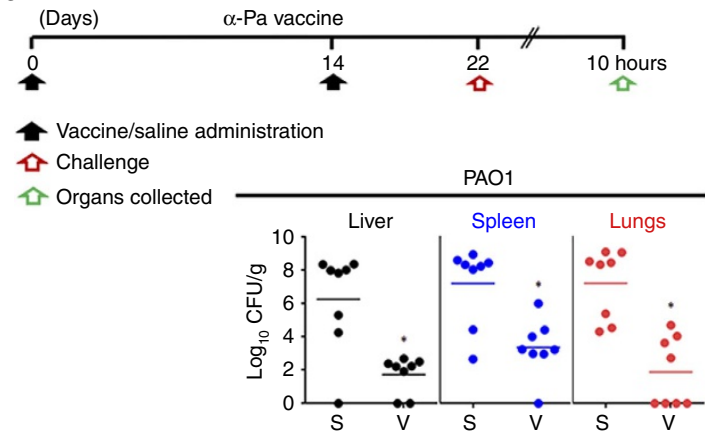

C

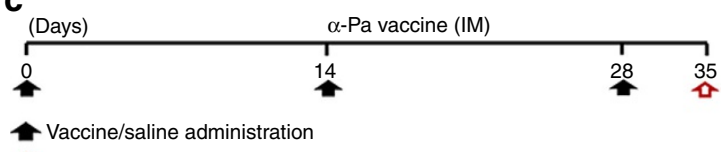

ث) Challenge
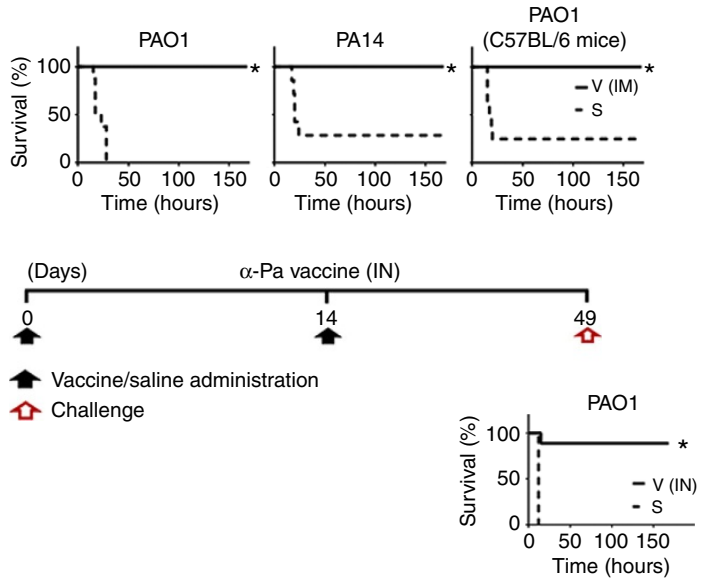

e

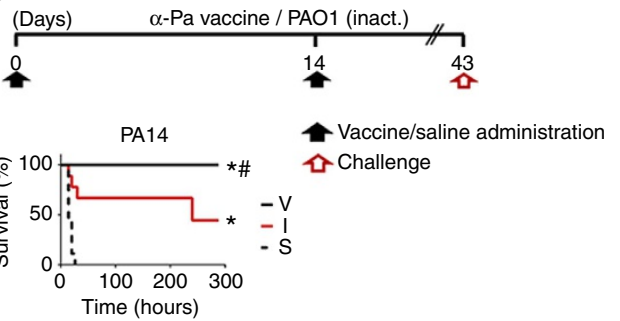

b
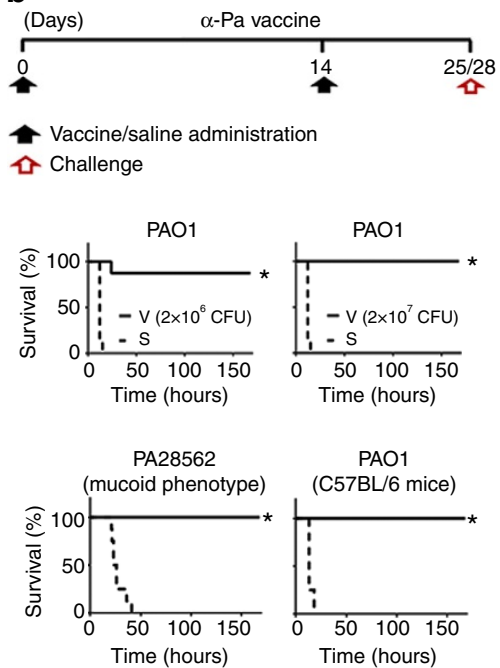

d
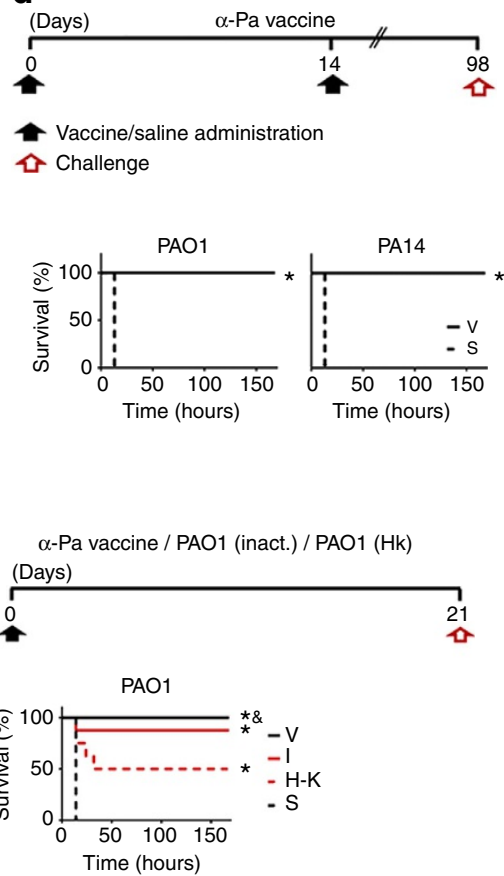

Figure 7 | Immunization with $\boldsymbol{P}$, aeruginosa D-Glu auxotroph ( $\boldsymbol{\alpha}$-Pa vaccine) provides effective protection against diverse bacteria. (a) Protective effect against bacterial dissemination after acute infection. Bacterial loads in tissues from vaccinated $\left(2 \times 10^{7} \mathrm{CFU}\right.$ of $\alpha$-Pa strain) and control mice after challenge with $P$. aeruginosa PAO1 $\left(2 \times 10^{7} \mathrm{CFU}\right)(n=8$; after $10 \mathrm{~h})$. ${ }^{\star} P<0.05$ (Mann-Whitney $U$-test). (b) Early vaccine protection against infection. Mice survival after vaccination with $\alpha$-Pa strain $\left(2 \times 10^{6}\right.$ and $\left.2 \times 10^{7} \mathrm{CFU}\right)$, or saline administration and challenge with PAO1 on day $25\left(2 \times 10^{7} \mathrm{CFU}, n=8\right.$ for BALB/C), on day $28\left(4 \times 10^{7} \mathrm{CFU}, n=4\right.$ for C57BL/6 mice) and PA28562 $\left(4 \times 10^{7} \mathrm{CFU}\right)$ on day $25(n=8)$. (c) Different routes of immunization and vaccine protection. Mice survival after IM vaccination with $\alpha$-Pa strain $\left(2 \times 10^{7} \mathrm{CFU}\right)$ or saline administration and challenge with PAO1 $\left(6 \times 10^{7} \mathrm{CFU}, n=8\right.$ for $\mathrm{BALB} / \mathrm{C}$ and $2 \times 10^{7} \mathrm{CFU}, n=8$ for C57BL/6) and PA14 $\left(4 \times 10^{6} \mathrm{CFU}\right)(n=7-8)$. Mice survival after intranasal (IN) vaccination with $\alpha-\mathrm{Pa}$ strain $\left(2 \times 10^{7}\right.$ CFU) or saline administration and challenge with PAO1 $\left(5 \times 10^{6} \mathrm{CFU}\right)(n=9)$. (d) Long-term vaccine protection against infection. Mice survival after vaccination with $\alpha$-Pa strain $\left(2 \times 10^{7}\right.$ CFU) or saline administration and challenge with PAO1 $\left(2 \times 10^{7}\right.$ CFU) on day 98 ( $\left.n=9-10\right)$ and PA14 on day 98 $\left(4 \times 10^{6} \mathrm{CFU}\right)(n=10)$. (e) Superior vaccine protection conferred by $P$. aeruginosa D-Glu auxotroph. Mice survival after vaccination with $\alpha$-Pa strain $\left(2 \times 10^{7} \mathrm{CFU}\right)$, formalin-inactivated PAO1 $\left(2 \times 10^{7} \mathrm{CFU}\right)$ or saline administration and challenge with PA14 $\left(8 \times 10^{6} \mathrm{CFU}\right)(n=9)$. Mice survival after vaccination with $\alpha$-Pa strain $\left(2 \times 10^{7} \mathrm{CFU}\right)$, formalin-inactivated PAO1 $\left(2 \times 10^{7} \mathrm{CFU}\right)$, heat-killed PAO1 $\left(2 \times 10^{7} \mathrm{CFU}\right)$ or saline administration and challenge with PAO1 ( $\left.4 \times 10^{7} \mathrm{CFU}\right)(n=8)$. (a-e) S, saline; I, administered the formalin-inactivated vaccine; $\mathrm{H}-\mathrm{K}$, administered the heat-killed vaccine; $\mathrm{V}$, vaccinated. (b-e) ${ }^{\star} P<0.05$ (log-rank test), compared with saline group. (e) $\# P<0.05$ (log-rank test), compared with mice administered the formalin-inactivated vaccine. $\& p<0.05$, compared with mice administered the heat-killed vaccine.

prevent lethal outcome derived from systemic infections. All mice administered with $\alpha-\mathrm{Ab}$ serum and subsequently challenged with A. baumannii ATCC 17978 and AbH12-A2 survived, whereas 100 and $75 \%$ of mice receiving naive serum succumbed to infection, respectively (Fig. 9b). Similarly, $100 \%$ of survival was observed for mice administered 
a
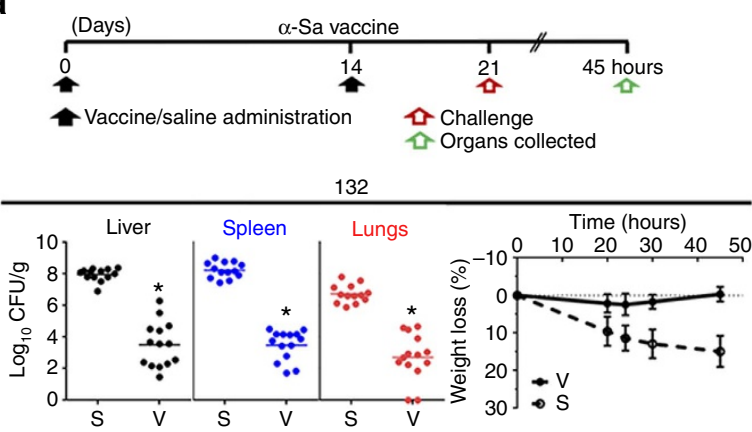

b

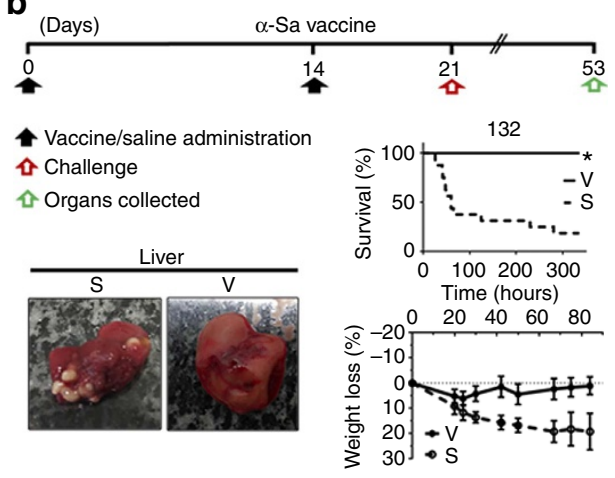

c
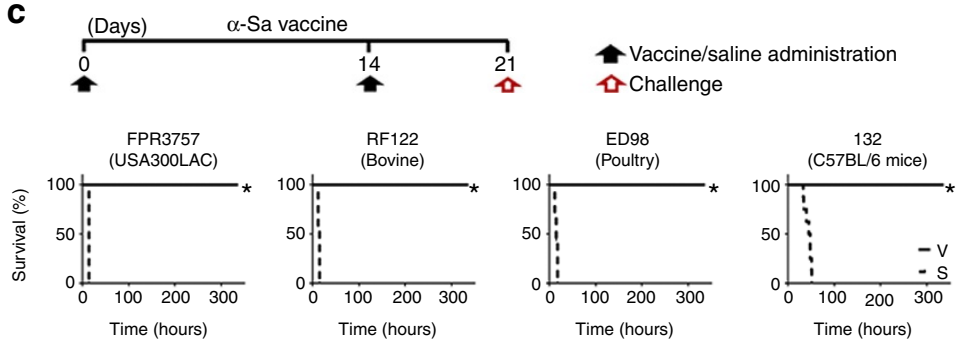

f

$\alpha$-Sa vaccine / 132 (inact.) / 132 (Hk) (Davs)

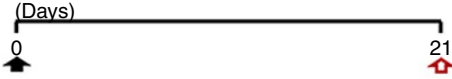

- Vaccine/saline administration

드allenge

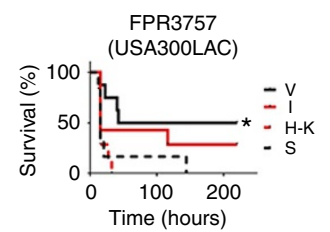

d
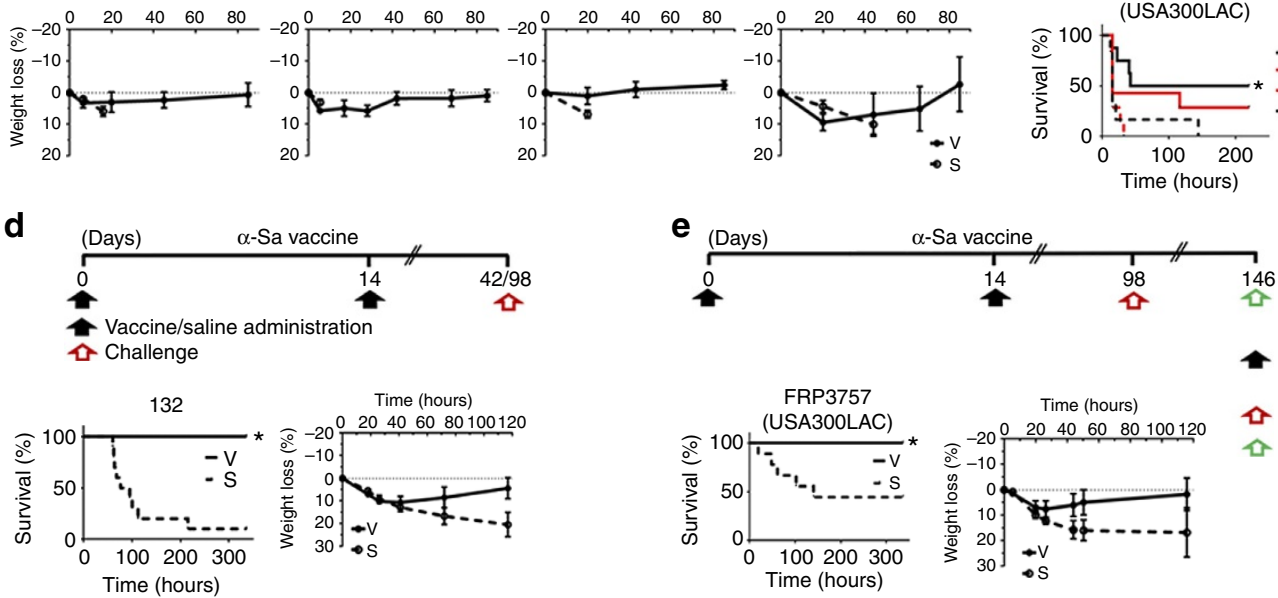

Vaccine/

saline administration ธ Challenge

늠 Organs collected
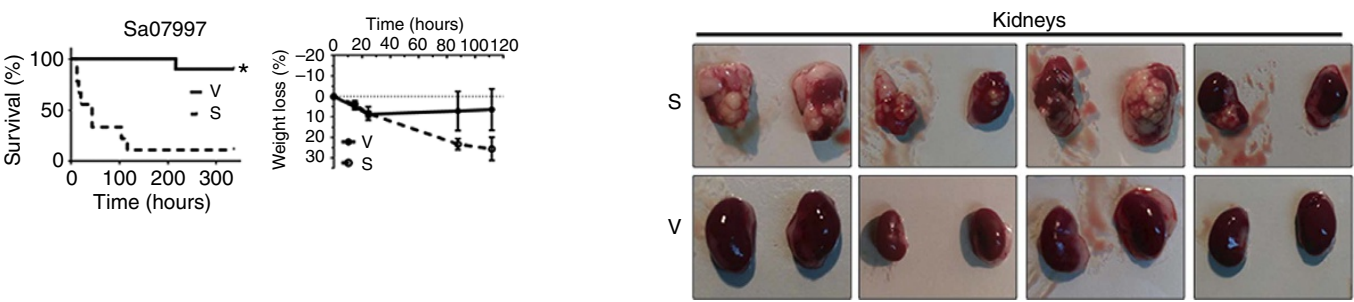

Figure 8 | Immunization with S. aureus D-Glu auxotroph ( $\alpha$-Sa vaccine) provides effective protection against diverse bacteria. (a) Protective effect against bacterial dissemination and body weight loss after acute infection. Bacterial loads in tissues and percentage of body weight loss (mean \pm s.e.m.) from vaccinated ( $3 \times 10^{7} \mathrm{CFU}$ of $\alpha$-Sa strain) and control mice after challenge with S. aureus $132\left(3 \times 10^{7} \mathrm{CFU}\right.$ with $3 \%$ of mucin; $n=14$, pooled data set from two independent experiments; after $45 \mathrm{~h}$ ). (b) Early vaccine protection against infection, body weight change and infectious abscesses. BALB/c mice survival and percentage of body weight loss (mean \pm s.e.m.) after vaccination with $\alpha$-Sa strain $\left(3 \times 10^{7} \mathrm{CFU}\right)$ or saline administration and challenge with $\mathrm{S}$. aureus 132 ( $3 \times 10^{7}$ CFU with $3 \%$ of mucin) ( $n=16-17$, pooled data set from two independent experiments). Images show livers collected at day 53 from random saline and vaccinated mice. (c) Early vaccine protection against infection and body weight change. Mice survival and percentage of body weight loss (mean \pm s.e.m.) after vaccination with $\alpha$-Sa strain $\left(3 \times 10^{7} \mathrm{CFU}\right)$ or saline administration and challenge with S. aureus FPR3757-USA30OLAC $\left(1.5 \times 10^{7} \mathrm{CFU}\right)(n=7), \mathrm{RF} 122\left(3 \times 10^{7} \mathrm{CFU}\right)(n=7)$, ED98 $\left(1 \times 10^{7} \mathrm{CFU}\right)(n=7)$ and $132\left(7 \times 10^{7} \mathrm{CFU} ; n=8\right.$, for C57BL/6 mice). (d) Long-term vaccine protection against infection and body weight change. Mice survival and percentage of body weight loss (mean \pm s.e.m.) after vaccination with $\alpha$-Sa strain $\left(3 \times 10^{7}\right.$ CFU) or saline administration and challenge with S. aureus 132 ( $3 \times 10^{7}$ CFU with $3 \%$ of mucin) on day $98(n=10)$ and Sa07997 $\left(1.3 \times 10^{7}\right.$ CFU with $3 \%$ of mucin) on day $42(n=9)$. (e) Long-term vaccine protection against infection, body weight change and infectious abscesses. Mice survival and percentage of body weight loss (mean \pm s.e.m.) after vaccination with $\alpha$-Sa strain $\left(3 \times 10^{7} \mathrm{CFU}\right)$ or saline administration and challenge with S. aureus FPR3757-USA30OLAC $\left(1 \times 10^{7} \mathrm{CFU}\right)(n=9-10)$. Images show kidneys collected at day 146 from random saline and vaccinated mice. (f) Superior vaccine protection conferred by S. aureus D-Glu auxotroph survival rates. Mice survival after vaccination with $\alpha$-Sa strain $\left(2 \times 10^{7}\right.$ $\mathrm{CFU})$, formalin-inactivated $132\left(2 \times 10^{7} \mathrm{CFU}\right)$, heat-killed $132\left(2 \times 10^{7} \mathrm{CFU}\right)$ or saline administration and challenge with FPR3757-USA300LAC $\left(2.7 \times 10^{7} \mathrm{CFU}\right.$ with $3 \%$ of mucin) $(n=6-8)$. (a-e) S, saline; I, administered the formalin-inactivated vaccine; $\mathrm{H}-\mathrm{K}$, administered the heat-killed vaccine; $\mathrm{V}$, vaccinated. (a) ${ }^{\star} P<0.05$ (Mann-Whitney $U$-test). (b-e) ${ }^{\star} P<0.05$ (log-rank test), compared with saline group. 

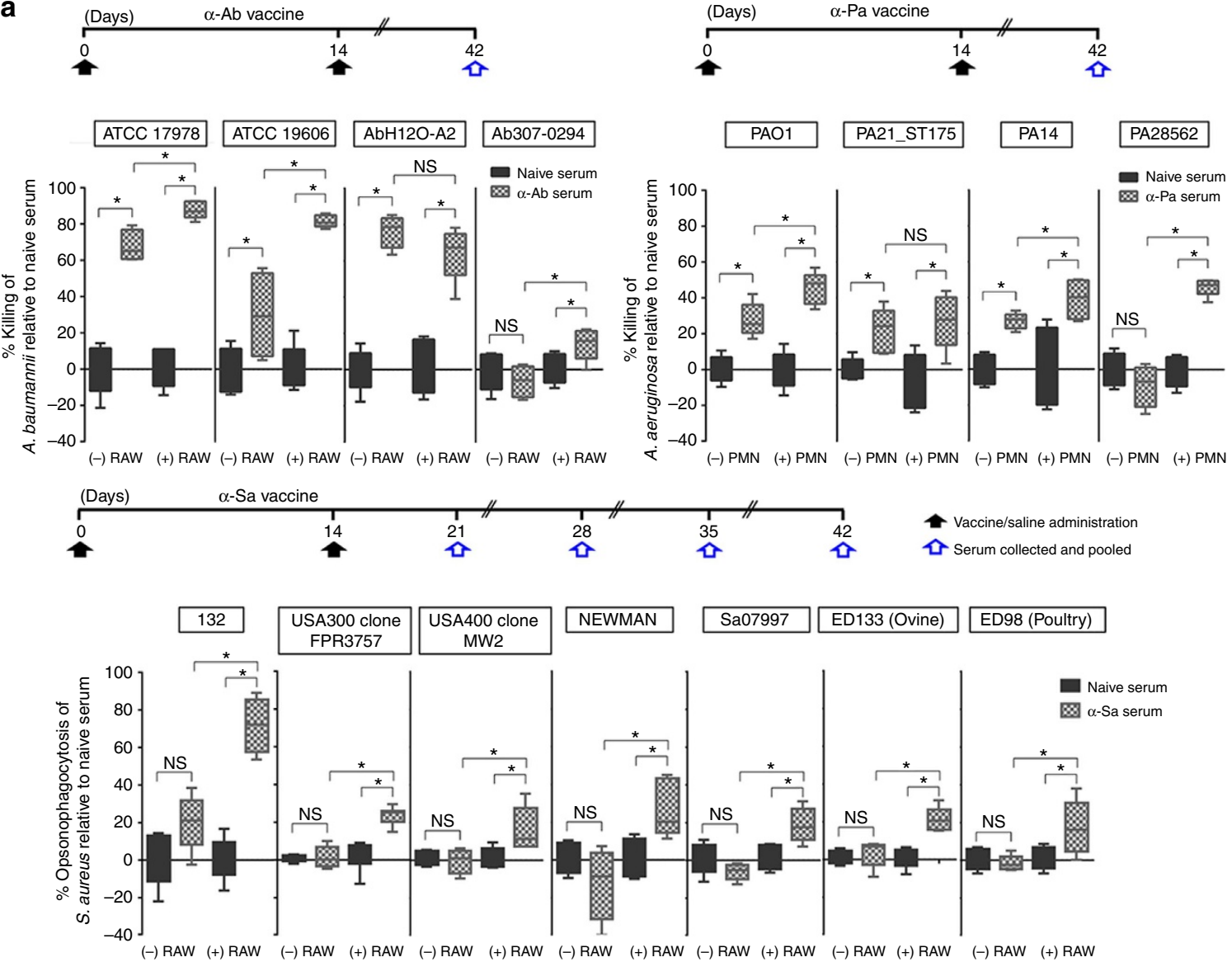

b
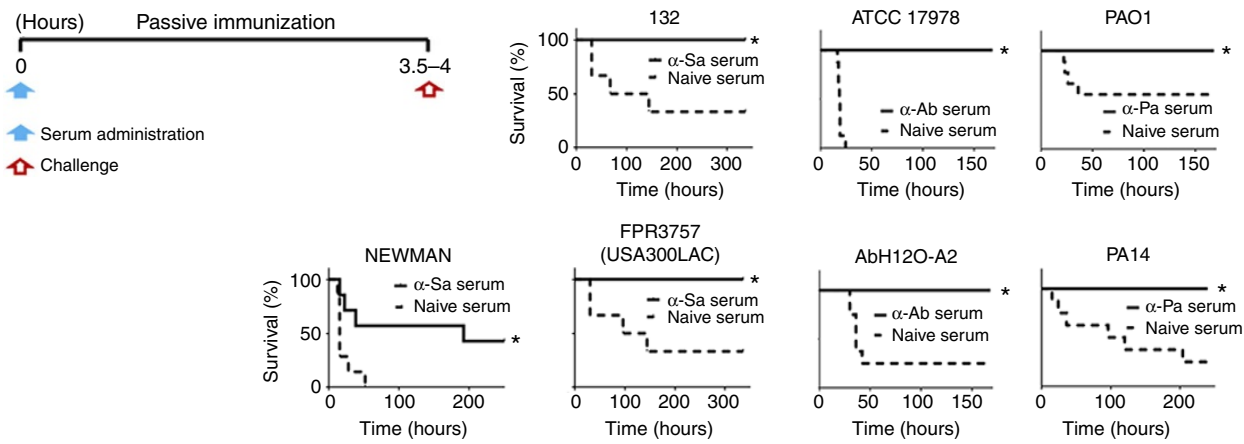

Figure 9 | Immunization with D-Glu auxotrophs generates functional and cross-reactive vaccine antisera. (a) In vitro OPA and OPKA assays. Per cent killing of A. baumannii ATCC 17978 ( $\left.4 \times 10^{4} \mathrm{CFU}\right)$, ATCC $19606\left(6 \times 10^{4} \mathrm{CFU}\right)$, AbH12O-A2 $\left(6 \times 10^{4} \mathrm{CFU}\right)$ and Ab307-0294 (4 × 10 4 CFU) strains, by $\alpha$-Ab serum (or naive serum) in the absence or presence of murine RAW 264.7 cells $\left(1.6 \times 10^{5}\right)$. Per cent killing of $P$. aeruginosa PAO1 ( $4 \times 10^{4}$ CFU), PA21_ST175 $\left(3 \times 10^{4} \mathrm{CFU}\right)$, PA14 $\left(4 \times 10^{4} \mathrm{CFU}\right)$ and PA28562 $\left(1 \times 10^{4} \mathrm{CFU}\right)$ strains by $\alpha$-Pa serum (or naive serum) in the absence or presence of human PMNs. Per cent opsonophagocytosis of $S$. aureus $132\left(1.2 \times 10^{4} \mathrm{CFU}\right)$, FPR3757 $\left(2.7 \times 10^{4} \mathrm{CFU}\right), \mathrm{MW} 2\left(1.8 \times 10^{4} \mathrm{CFU}\right), \mathrm{NEWMAN}\left(1.5 \times 10^{4} \mathrm{CFU}\right)$, Sa07997 (3.6 $\left.\times 10^{4} \mathrm{CFU}\right), \mathrm{ED} 133\left(4 \times 10^{4} \mathrm{CFU}\right)$ and ED98 $\left(7 \times 10^{4} \mathrm{CFU}\right)$ strains by $\alpha$-Sa serum (or naive serum) in the absence or presence of murine RAW 264.7 cells $\left(1.6 \times 10^{5}\right)$. ${ }^{\star} P<0.05$ (Student's $t$-test), compared with naive serum or the absence of RAW/PMN cells. (b) In vivo passive immunizations performed with BALB/c mice administered $\alpha-\mathrm{Ab}, \alpha-\mathrm{Pa}, \alpha$-Sa or naive sera and challenged with ATCC $17978\left(4 \times 10^{8} \mathrm{CFU}\right)(n=8), \mathrm{AbH} 12 \mathrm{O}-\mathrm{A} 2\left(1.4 \times 10^{8}\right.$ $\mathrm{CFU})(n=8)$, PAO1 $\left(2 \times 10^{7} \mathrm{CFU}\right)(n=8), \mathrm{PA} 14\left(2 \times 10^{7} \mathrm{CFU}\right)(n=8), 132\left(7.5 \times 10^{7} \mathrm{CFU}\right)(n=6), \mathrm{FPR} 3757\left(1.5 \times 10^{7} \mathrm{CFU}\right)(n=6)$ and NEWMAN $\left(5.3 \times 10^{7} \mathrm{CFU}\right)(n=7)$ strains, $3.5-4 \mathrm{~h}$ after serum administration. ${ }^{\star} P<0.05$ (log-rank test), compared with naive serum.

with $\alpha$-Pa serum and challenged with $P$. aeruginosa PAO1 and PA14 strains. Survival for controls receiving naive serum was $56 \%$ and $25 \%$, respectively. Mice administered $\alpha$-Sa serum and challenged with $S$. aureus 132 and FRP3757USA300LAC strains also showed $100 \%$ survival while $67 \%$ of controls receiving naive serum succumbed to infection in both assays. The passive transfer of $\alpha$-Sa serum resulted in a significant survival rate of mice (43\%) $(P<0.05$, log-rank test), compared to mice receiving naive serum $(0 \%)$, after challenge with NEWMAN strain.

Overall, these results indicate that vaccine antisera can effectively enhance bacterial clearance and offer protection against lethal infections caused by a global spectrum of heterologous and relevant strains of these pathogens. 
Safety profiles of D-Glu auxotroph vaccines. Finally, the attenuation should be carried out in such a way that does not allow a persistent carrier state of the vaccine ${ }^{33}$. This can be achieved by the auxotrophic strain's ability to colonize and multiply in the host over a limited period being eliminated without causing the disease. This was observed for the three auxotrophic strains when injected intravenously and IP to mice, as they were completely cleared from blood (Supplementary Fig. 9a). In addition, the IP administration of D-Glu auxotrophic strains did not affect mice body weight significantly, as no differences were observed between vaccinated and saline (vehicle) control mice (Supplementary Fig. 9b).

In summary, these observations support that D-Glu auxotrophs present good safety profiles for parenteral administrations.

\section{Discussion}

Having a whole-cell vaccine that contains all the antigenic determinants to induce protective immunity, including those that are only expressed in vivo, without the risk of clinical infection and with minimal possibilities of adverse reactions, is the paradigm for effective and safe immunizations. Some of these aspects can be afforded by live-attenuated vaccines obtained by natural selection or genetic engineering of bacterial strains. However, they require particular attention regarding their safety as they may propagate and be released into the environment by the vaccinees ${ }^{30}$. Furthermore, obtaining virulence attenuation is usually impeded by the laborious identification of rational targets in each particular bacterium.

Although D-amino acids are increasingly recognized as physiologically functional molecules in mammals, the amounts of free D-Glu are trace substances in most cases ${ }^{34}$. By abrogating D-Glu synthesis, we took advantage of the highly-conserved function of MurI and the strict requirement of sufficient D-Glu pool levels to impair bacterial replication in the mammal host. Indeed, $A$. baumannii, $P$. aeruginosa and $S$. aureus D-Glu auxotrophs are incapable of proliferating in the mouse due to the blockage of the cell wall synthesis being attenuated in comparison with the parental strains. These GMOs triggered appropriate cellular immune responses and the production of specific and cross-reactive antibodies to several clonally unrelated epidemic, MDR and highly virulent strains. These results correlated with protection against acute lethal infections mainly using a two-dose immunization schedule and the IP route, although intramuscular and intranasal vaccinations were also effective. D-Glu auxotrophs also conferred superior vaccine efficacy with respect to formalininactivated or heat-killed wild-type bacteria. In addition, these vaccine strains did not appear to represent a risk for causing disease and spreading to non-target recipients, considering their rapid elimination from the blood and their limited persistence in non-optimal conditions, more likely to occur in the hypothetical case of an accidental environmental release. Altogether, these attributes constitute advantages of D-Glu auxotrophic vaccines over live-attenuated or inactivated. Other auxotrophic bacterial strains carrying mutations in aromatic amino acid and/or purine biosynthetic pathways have also been described as potential live vaccine candidates ${ }^{35-40}$. Generally, these auxotrophs have a limited ability to undergo replication in the host with survival duration ranging from days to weeks, which is higher than the observed persistence for D-Glu auxotrophs. Moreover, their level of attenuation and their ability to confer efficacy will rely on the bacteria, the enzymatic step disrupted and the animal model utilized.

MDR or pandrug-resistant A. baumannii strains are responsible of an escalating number of infections ${ }^{41}$ and therefore, prophylactic vaccination represents an option for the future ${ }^{42,43}$.
So far, several preclinical experimental vaccines have been described $^{6,43}$. Particularly, inactivated whole cells can elicit better vaccine coverage, but the high endotoxin levels (LPS) complicate their use in humans. Although LPS-deficient inactivated whole cells could be a good vaccine ${ }^{44}$, the lack of the immunostimulatory LPS may impair immunogenicity. In contrast, $\mathrm{Ab} \mathrm{MurI}^{-}$seems not to pose a risk for endotoxin accumulation in view of the rapid elimination from the blood of mice and the absence of adverse effects. Little is known regarding the pathogenesis and the immune responses against $A$. baumannii disease. Ab MurI ${ }^{-}$was found to elicit high levels of opsonic, bactericidal and cross-reactive antibodies, probably due to the presentation of whole-cell antigens. Considering the cellular immunity, a significant increment in IL-4- and IL-17producing splenocytes was obtained, which is consistent with a Th2/Th17 response.

Despite the research efforts, there is no vaccine against $P$. aeruginosa licensed yet. Effective immunotherapies or vaccines have long been sought as alternatives to prevent $P$. aeruginosa infections $3,45,46$. The closest strategy of vaccine design included the introduction of mutations into the aro $A$ gene for the creation of live-attenuated strains $37,39,40,47$. These mutants are unable to synthesize aromatic amino acids and cannot efficiently acquire them from the host, surviving at detectable levels in the lungs up 3-4 days following administration ${ }^{37}$. In our study, $\mathrm{Pa} \mathrm{MurI}^{-}$was shown to be eliminated from blood until $10 \mathrm{~h}$ after intravenous administration suggesting a lesser risk of side effects. As $P$. aeruginosa is an extracellular pathogen, a strong opsonophagocytic antibody response is generally predictive for protection, as observed in our work. However, T-cell responses can also mediate protective immunity ${ }^{48}$. Pa MurI ${ }^{-}$triggered a substantial increment in IL-4-producing splenocytes, consistent with a Th2 immune response. IL- 4 is known to enhance pulmonary clearance of $P$. aeruginosa in mice ${ }^{49}$. More importantly, Pa MurI ${ }^{-}$mediated a significant increase in the number of IL-17-secreting splenocytes, essential in clearance of acute pulmonary $P$. aeruginosa infection ${ }^{50}$.

$S$. aureus is a leading cause of healthcare- and communityacquired infections worldwide, affecting virtually all human and animal tissues ${ }^{4}$. Despite continuous efforts, active immunizations have been largely unsuccessful in human clinical trials $2,51-54$ Potential reasons underlying these vaccine failures have been identified $^{55-58}$. Apparently, there is only one whole-cell vaccine, composed by an inactivated SA75 strain, in the pipeline to prevent human infections ${ }^{52,59}$. Although it completed a phase I trial successfully, it appears to be no longer under active development. Moreover, only antibody responses were measured, without determining their functionality or measuring T-cell responses. In turn, auxotrophic aro $A$ mutants have been tested in a preclinical inframammary mouse model to target $S$. aureus-mastitis in dairy cattle $^{38}$, but seems not to be suitable for safe immunizations others than intramammary. Indeed, $57 \%$ of mice succumbed after the intravenous injection of $2 \times 10^{7} \mathrm{CFU}$ of the $\operatorname{aro} A$ mutant. In contrast, we showed that an equivalent dose of Sa MurI ${ }^{-} \mathrm{Dat}^{-}$ was completely cleared from the mouse blood without causing disease. The immune protection of $S$. aureus vaccines is a matter of some debate. The current consensus establishes that cellmediated immunity (Th1/Th17) and neutrophil activation may be required for effective protection, while antibodies may play a supportive role for opsonization and/or neutralization of virulence factors $51,56,57$. In this sense, live-attenuated vaccines may offer an advantage over inactivated formulations, such as SA75 vaccine, considering they elicit effective cellular immune responses. Indeed, Sa MurI ${ }^{-}$Dat $^{-}$immunization triggered not only functional and cross-reactive antibodies but an increase in 
the number of IFN- $\gamma$ - and IL-17-secreting splenocytes that correlated with long-term protection. As previously noted, Th1 effector cytokines such as IFN- $\gamma$ may play a crucial role in the eradication of $S$. aureus ${ }^{60,61}$, while Th17/IL-17 pathway may collaborate in promoting neutrophil recruitment ${ }^{62}$, and was demonstrated to be essential for combating $S$. aureus sepsis and pneumonia in mice 8 ,63-65.

Although with substantial differences among the three targeted pathogens, the D-Glu auxotrophic vaccines tested here in mice conferred long-term survival (up to three months) after immunization against lethal systemic infections. The protection observed could be derived from the combination of opsonic antibodies as well as concomitant T-cell responses, with IL-17 cytokine playing a relevant role, the common features observed amongst the three vaccine prototypes.

For all the above reasons, we believe that our D-Glu auxotrophs are promising candidates to be developed as wholecell vaccines against the high-priority pathogens $A$. baumannii, $P$. aeruginosa and $S$. aureus, and that our approach for bacterial attenuation can potentially be applied to many other gramnegative and gram-positive pathogens for their potential use as prophylactics for human or animal health.

\section{Methods}

Bacterial strains and growth conditions. All bacterial strains and plasmids used in this study are listed in Supplementary Table 1. We selected A. baumannii ATCC 17978, P. aeruginosa $\mathrm{PAO}$ and S. aureus 132 for genetic manipulation to generate the indicated mutant strains. S. aureus 132 is an MRSA strain isolated from a patient at the Microbiology Department of the Clínica Universitaria de Navarra (Pamplona, Spain). This strain can produce alternative biofilm matrix depending on environmental conditions consisting of proteins or exopolysaccharides ${ }^{29}$. All Escherichia coli, A. baumannii and P. aeruginosa strains were grown in LuriaBertani broth (LB: $10 \mathrm{gl}^{-1}$ tryptone, $5 \mathrm{gl}^{-1}$ yeast extract, $10 \mathrm{gl}^{-1}$ sodium chloride) or on LB agar at $37^{\circ} \mathrm{C}$ unless otherwise stated. S. aureus and CoN Staphylococci strains were grown in Tryptic Soy Broth (TSB) or on TSB agar at $37^{\circ} \mathrm{C}$ unless otherwise stated. Ampicillin, kanamycin, gentamycin and erythromycin, when appropriate for plasmid selection, were added at a concentration of $100,50,30$ and $10 \mu \mathrm{g} \mathrm{ml}^{-1}$, respectively. X-Gal (5-bromo-4chloro-3-indolyl $\beta$-D-galactopyranoside) was used at a concentration of $150 \mu \mathrm{g} \mathrm{ml}^{-1}$. All primers and chemicals were purchased from Sigma-Aldrich (Madrid, Spain), unless mentioned.

Construction of unmarked deletion mutants. We used in vitro methods to construct mutant alleles, designated $\Delta$ murI1 and $\Delta$ murI2 in A. baumannii ATCC 17978, $\Delta$ murI in P. aeruginosa PAO1, $\Delta m u r I$ and $\Delta$ dat in S. aureus 132 with inframe deletions corresponding to murI1, murI2, murI, murI and dat genes, respectively. These mutant alleles were replaced, either singly or together, by the corresponding wild-type alleles using the previously described allelic exchange systems with the pMo130, pEX18Gm and pMAD plasmids in A. baumannii, $P$. aeruginosa and S. aureus, respectively ${ }^{66-68}$. Primers used are listed in

Supplementary Table 2. For A. baumannii, fragments of about $1 \mathrm{~kb}$ corresponding to the upstream and downstream regions of murI1 and murI2 were amplified by PCR with the combination of primers UP_murIl(NotI)/UP_murII(BamHI), DOWN_murII(BamHI)/DOWN_murI1(SphI), UP_murI2(NotI)II/ UP_murI2(BamHI)II and DOWN_murI2(BamHI)/DOWN_murI2(SphI). The upstream fragments obtained were digested with NotI and BamHI restriction enzymes; downstream fragments were digested with BamHI and SphI. Digested products were ligated into pMo130, which was previously linearized with NotI and SphI and the recombinant plasmids pMo130_UP/DOWN_murI1 and pMo130_UP/DOWN_murI2 obtained were independently transformed in E. coli S17-1 by electroporation. S17-1 transformants were selected on LB containing kanamycin, sprayed with pyrocatechol, and only yellow colonies expressing the $x y l E$ reporter gene were analysed by PCR to confirm the presence of the recombinant plasmids, that were then individually introduced in A. baumannii ATCC 17978 by electroporation. A. baumannii bright yellow and kanamycinresistant colonies, representing the first crossover event, were grown on LB supplemented with $15 \%$ sucrose for $6 \mathrm{~h}$, and then plated on the same agar medium. The resulting white colonies (after spraying with pyrocatechol) were analysed by PCR (using the combination of primers EXTfw_murI1/EXTrv_murI1, EXTfw_murI2/EXTrv_murI2, INTfw_murI1/INTrv_murI1, INTfw_murI2/ INTrv_murI2) to confirm the second crossover event resulting in $\Delta$ murI1 and $\Delta$ murI2 genotypes, produced by the allelic exchange of plasmids pMo130_UP/ DOWN_murI1 and pMo130_UP/DOWN_murI2 with the murI1 and murI2 alleles, respectively. The pMo130_UP/DOWN_murI2 plasmid was also introduced in the ATCC $17978 \Delta$ murI1 mutant previously obtained, by electroporation.
Transformant bright yellow and kanamycin-resistant colonies, were then grown on LB containing 15\% sucrose and supplemented with $10 \mathrm{mM} \mathrm{D}$-Glu for $6 \mathrm{~h}$, and plated on the same agar medium. The resulting white colonies (after spraying with pyrocatechol) were picked from agar plates containing $10 \mathrm{mM} \mathrm{D-Glu} \mathrm{and}$ inoculated in patches at comparable locations on LB agar plates with and without $10 \mathrm{mM}$ D-Glu. Presumptive colonies with the $\Delta$ murI1 $\Delta$ murI2 double-mutant genotype that grew only on D-Glu containing plates, were analysed by PCR using the primers EXTfw_murI2/EXTrv_murI2 and INTfw_murI2/INTrv_murI2 to confirm the second crossover event, produced by the allelic exchange of plasmid pMo130_UP/DOWN_murI2 with the murI2 allele. For P. aeruginosa, fragments of about $1 \mathrm{~kb}$ in length corresponding to the upstream and downstream regions of the murI gene were amplified by PCR with the combination of primers UP_murI(HindIII)II/UP_murI(NotI) and DOWN_murI(NotI)/ DOWN_murI(XbaI). The upstream fragment obtained was digested with HindIII and NotI restriction enzymes; the downstream fragment was digested with NotI and XbaI. Digested products were ligated into pEX18Gm, which was previously linearized with HindIII and XbaI and the recombinant plasmid pEX18Gm_UP/ DOWN_murI obtained was transformed in E. coli S17-1 by electroporation. S17-1 transformants were selected on LB containing gentamycin and were analysed by PCR to confirm the presence of the recombinant plasmid, which was then introduced in P. aeruginosa PAO1 by electroporation. P. aeruginosa gentamycinresistant colonies, representing the first crossover event, were grown on LB containing $15 \%$ sucrose and $10 \mathrm{mM} \mathrm{D}$-Glu for $6 \mathrm{~h}$, and plated on the same agar medium. The resulting colonies were picked from agar plates containing $10 \mathrm{mM}$ D-Glu and inoculated in patches at comparable locations on LB agar plates with and without $10 \mathrm{mM}$ D-Glu. Presumptive colonies with the $\Delta m u r I$ mutant genotype that grew only on D-Glu containing plates, were analysed by PCR using the primers EXTfw_murI/EXTrv_murI and INTfw_murI/INTrv $\_$murI to confirm the second crossover event, produced by the allelic exchange of plasmid pEX18Gm_UP/DOWN_murI with the murI allele. For S. aureus, fragments of $1 \mathrm{~kb}$ corresponding to the upstream and downstream flanking regions of murI and dat genes were amplified by PCR using primers UP_murI(MluI)/UP_murI(NotI), DOWN_murI(NotI)/DOWN_murI(BglII), UP_dat(MluI)/UP_dat(NotI) and DOWN_dat(NotI)/DOWN_dat(BglII), and next digested by the restriction enzymes indicated within brackets. Digested products were ligated into pMAD, previously linearized with MluI and BglII. The resulting pMAD_UP/DOWN_murI and PMAD_UP/DOWN_dat plasmids were confirmed by sequencing and independently transformed by electroporation into E. coli TG1 and DC10 $\beta$, respectively. For the allelic exchange of pMAD_UP/DOWN_murI with the murI allele, the recombinant plasmid was transformed in S. aureus RN4220 and then in S. aureus 132 by electroporation. For the allelic exchange of pMAD_UP/ DOWN_dat with the dat allele, the recombinant plasmid was directly introduced into S. aureus 132 from E. coli DC10 $\beta$. Homologous recombination experiments were performed as follows: one blue erythromycin-resistant colony of $S$. aureus containing pMAD_UP/DOWN_murI or pMAD_UP/DOWN_dat was grown in TSB with erythromycin at $30^{\circ} \mathrm{C}$ for $2 \mathrm{~h}$ and then, at $43.5^{\circ} \mathrm{C}$, a non-permissive temperature for pMAD replication. Resulting cultures were serially diluted and light blue erythromycin-resistant colonies, representing the first crossover event, were selected at $43.5^{\circ} \mathrm{C}$ on TSB plates with erythromycin and X-Gal. Several of these colonies were grown in TSB without antibiotic at $30^{\circ} \mathrm{C}$ for $18 \mathrm{~h}$, and then plated on the same agar medium. The resulting white colonies were analysed by PCR and sequencing (using the combination of primers EXTfw_murI/ EXTrv_murI, INTfw_murI/INTrv_murI, EXTfw-seq- UP_murI/EXTrv-seqDOWN_murI, EXTfw_dat/EXTrv_dat, INTfw_dat/INTrv_dat and EXTfw-seqUP_dat/EXTrv-seq-DOWN_dat, designed for $\bar{S}$. aureus) to confirm the $\Delta$ murI and $\Delta$ dat genotypes produced by the allelic exchange of plasmids pMAD_UP/ DOWN_murI and pMAD_UP/DOWN_dat with the murI and dat alleles, respectively. pMAD_UP/DOWN_dat plasmid was also introduced by electroporation in the $132 \Delta$ murI mutant. Transformant blue erythromycinresistant colonies were firstly grown in TSB at $30^{\circ} \mathrm{C}$ and then, at $43.5^{\circ} \mathrm{C}$ to obtain colonies resulting from the first crossover. Several of these colonies were transferred to TSB with $10 \mathrm{mM} \mathrm{D}$-Glu, incubated at $30^{\circ} \mathrm{C}$ for $18 \mathrm{~h}$ and then plated on the same agar medium. The resulting white colonies were picked and inoculated in patches at comparable locations on TSB agar plates with and without $10 \mathrm{mM}$ D-Glu. Presumptive colonies with the $\Delta$ murI $\Delta$ dat double-mutant genotype that grew only with D-Glu were confirmed for the second crossover event, produced by the allelic exchange of the plasmid pMAD_UP/DOWN_dat with the dat allele, by PCR and sequencing using the primers EXTfw_dat/ EXTrv_dat, INTfw_dat/INTrv_dat and EXTfw-seq-UP_dat/EXTrv-seqDOWN_dat.

Restriction enzymes, GoTaq DNA polymerase and T4 DNA Ligase were purchased from Promega Biotech Ibérica (Madrid, Spain) and used as recommended by the supplier. The Expand High Fidelity PCR System was obtained from Roche Farma (Madrid, Spain). Plasmid DNA isolation from E. coli was achieved using the Wizard Plus SV Minipreps DNA Purification System, from Promega or the Plasmid Midi Kit, from Qiagen (Hilden, Germany). Genomic DNA from A. baumannii and P. aeruginosa was obtained using the High Pure PCR Template Preparation Kit, from Roche. Genomic DNA from S. aureus was obtained using the Wizard Genomic DNA Purification Kit, from Promega. Electrotransformation of A. baumannii, E. coli, P. aeruginosa and S. aureus was performed according to the Gene Pulser Xcell Electroporation 
System instructions, Bio-Rad Laboratories (Madrid, Spain) or protocols described elsewhere ${ }^{69}$.

Growth and viability curves. To determine the growth and viability of $A$. baumannii ATCC $17978(\mathrm{Ab})$, P. aeruginosa PAO1 $(\mathrm{Pa})$ and derived mutant strains, these bacterial strains were cultured overnight at $37^{\circ} \mathrm{C}$ and 180 r.p.m. in $5 \mathrm{ml} \mathrm{LB}$ supplemented with $10 \mathrm{mM}$ D-Glu. Bacterial cultures were centrifuged (4,000 g, $15 \mathrm{~min}$ ) and the pellets were washed twice with LB. After pellet suspension in $5 \mathrm{ml}$ $\mathrm{LB}, 100 \mu \mathrm{l}$ were used to inoculate $100 \mathrm{ml}$ of LB with or without $10 \mathrm{mM} \mathrm{D}$-Glu and left incubating at $37^{\circ} \mathrm{C}$ under agitation (180 r.p.m.). For $\mathrm{Ab}$ and derived mutants, samples were taken every $60 \mathrm{~min}$ for $7 \mathrm{~h}$ to determine the culture turbidity $\left(\mathrm{OD}_{600 \mathrm{~nm}}\right)$. In parallel, samples were taken every $2 \mathrm{~h}$ up to $6 \mathrm{~h}$ to determine CFU (colony-forming units) in LB agar with $10 \mathrm{mM}$ D-Glu. For Pa and Pa $\Delta m u r I$, samples were taken at $0,60,180,300,480$ and $1,320 \mathrm{~min}$ to determine the culture turbidity $\left(\mathrm{OD}_{600 \mathrm{~nm}}\right)$. In parallel, samples were taken at $0,180,480$ and $1,320 \mathrm{~min}$ to determine CFU in LB agar with $10 \mathrm{mM}$ D-Glu. In the case of $S$. aureus, overnight cultures of $S$. aureus 132 (Sa) and derived mutants were centrifuged (3,900 g, $20 \mathrm{~min}$ ) and the pellets washed once with TSB. After pellet suspension, cultures adjusted to $\mathrm{OD}_{600 \mathrm{~nm}}=2$ were used to inoculate $100 \mathrm{ml}$ of TSB with or without $20 \mathrm{mM}$ D-Glu ( $\times 10^{-2}$ dilution) and left incubating at $37^{\circ} \mathrm{C}$ under agitation ( 180 r.p.m.). Samples were taken at 0 and every $60 \mathrm{~min}$ up to $8 \mathrm{~h}$ to determine the culture turbidity $\left(\mathrm{OD}_{600 \mathrm{~nm}}\right)$. In parallel, samples were taken at $0,120,240,360$ and $480 \mathrm{~min}$ to determine CFU in TSB agar with $10 \mathrm{mM}$ D-Glu for Sa $\Delta m u r I \Delta d a t$ or without D-Glu for the remaining strains. All cultures were made in triplicate.

Real-time RT-PCR. We used quantitative real-time reverse transcription PCR (qRT-PCR) to examine Ab, Ab $\Delta$ murI1, Ab $\Delta$ murI2 and Ab $\Delta$ murI1 $\Delta$ murI2 strains for the expression of murI1 and murI2 genes; $\mathrm{Pa}$ and $\mathrm{Pa} \Delta$ murI strains for the expression of $m u r I$ gene; in turn, Sa, Sa $\Delta m u r I$, Sa $\Delta$ dat and Sa $\Delta m u r I \Delta d a t$ strains for the expression of murI and dat genes, using the Universal Probe Library TaqMan probes (Roche) or TaqMan probes specifically designed (TIB MOLBIOL, Berlin, Germany) together with the primers listed in Supplementary Table 2. Total DNase-treated RNA (500 ng for A. baumannii and $100 \mathrm{ng}$ for P. aeruginosa and S. aureus) was obtained from log-phase cultures $\left(\mathrm{OD}_{600 \mathrm{~nm}}=0.5-0.7\right)$ using the High Pure RNA Isolation Kit (Roche). For qRT-PCR, a LightCycler 480 RNA instrument and Master hydrolysis probes kit (both from Roche) were used together with the following protocol: initial incubation at $65^{\circ} \mathrm{C}, 3 \mathrm{~min}$, followed by a denaturation step at $95^{\circ} \mathrm{C}$ for $30 \mathrm{~s}, 45$ cycles at $95^{\circ} \mathrm{C}, 15 \mathrm{~s}$ and $60^{\circ} \mathrm{C}, 45 \mathrm{~s}$, and a final elongation step at $40^{\circ} \mathrm{C}, 30 \mathrm{~s}$. In all cases, the expression levels were normalized relative to the transcription levels of gyrB (A. baumannii and $S$. aureus) and proC ( $P$. aeruginosa) housekeeping genes, which were assigned a value of 1.0. All assays were performed using samples from three different RNA extractions.

Scanning electron microscopy. In order to take microphotographs by SEM, Ab, $\mathrm{Ab} \Delta m u r I 1 \Delta m u r I 2, \mathrm{~Pa}$ and $\mathrm{Pa} \Delta m u r I$ strains were cultured overnight at $37^{\circ} \mathrm{C}$ in $5 \mathrm{ml} \mathrm{LB}$ supplemented with $10 \mathrm{mM}$ D-Glu. Bacterial cultures were centrifuged $(4,000 \mathrm{~g}, 15 \mathrm{~min})$ and the pellets were washed twice with $0.9 \% \mathrm{NaCl}$. After pellet suspension in $5 \mathrm{ml} \mathrm{LB}, 1 \mathrm{ml}$ was used to inoculate $100 \mathrm{ml}$ of LB. The cultures were incubated at $37^{\circ} \mathrm{C}$ for $2 \mathrm{~h}$ under agitation (180 r.p.m.) and then centrifuged and washed twice with $0.9 \% \mathrm{NaCl}$. After pellet suspension in $100 \mathrm{ml} \mathrm{LB}, 50 \mu \mathrm{l}$ were used to inoculate $5 \mathrm{ml}$ of $\mathrm{LB}$ with D-Glu at $0,0.1,1.25$ and $10 \mathrm{mM}$. The cultures were incubated at $37^{\circ} \mathrm{C}$ under agitation ( 180 r.p.m.) for $2 \mathrm{~h}$ and were subsequently centrifuged and washed twice with PBS. Sa and Sa $\Delta m u r I \Delta$ dat strains were cultured overnight at $37^{\circ} \mathrm{C}$ in $5 \mathrm{ml}$ of TSB supplemented with $20 \mathrm{mM} \mathrm{D}$-Glu. Bacterial cultures were centrifuged $(3,900 \mathrm{~g}, 20 \mathrm{~min})$ and the pellets were washed twice with $0.9 \% \mathrm{NaCl}$. After pellet suspension in $1 \mathrm{ml} \mathrm{TSB}, 50 \mu \mathrm{l}$ of each suspension were used to inoculate $5 \mathrm{ml}$ of TSB with D-Glu at $0,0.1,1.5$ and $20 \mathrm{mM}$. Then cultures were incubated at $37^{\circ} \mathrm{C}$ with shaking (180 r.p.m.) for $3 \mathrm{~h}$ and were subsequently centrifuged and washed twice with PBS. The pellets were then fixed with $4 \%$ paraformaldehyde in $0.1 \mathrm{M}$ PBS $\mathrm{pH} 7.4$ for $30 \mathrm{~min}$ and washed again twice with PBS. Each sample was dehydrated in increasing series of ethanol $(50,70,90$ and $100 \%)$ for $10-15 \mathrm{~min}$ and then dried to the critical point with $\mathrm{CO}_{2}$ (Bal-Tec CPD 030). One drop of each sample was placed onto a slide cover and fixed in aluminium supports for gold coating (Bal-Tec SCD 004 sputter coater). Observation was conducted and photographs were taken using a Jeol JSM-6400 electron microscope.

Transmission electron microscopy. To take microphotographs using TEM, Ab, Ab $\Delta m u r I 1 \Delta m u r I 2, \mathrm{~Pa}, \mathrm{~Pa} \Delta m u r I, \mathrm{Sa}$ and Sa $\Delta m u r I \Delta d a t$ strains were cultured overnight at $37^{\circ} \mathrm{C}$ in LB or TSB agar supplemented with $10 \mathrm{mM} \mathrm{D}$-Glu. After incubation, 2-3 colonies of each strain were plated onto $\mathrm{MH}$ (Mueller Hinton), LB and $\mathrm{LB}$ supplemented with $\mathrm{MgCl}_{2}\left(30 \mathrm{mgl}^{-1}\right)$ and $\mathrm{CaCl}_{2}\left(75 \mathrm{mgl}^{-1}\right)$ and incubated overnight at $37^{\circ} \mathrm{C}$. After incubation, 2-3 colonies obtained in the first streak of each plate were dissolved in PBS buffer, the suspension was centrifuged and the resulting pellet was washed first with cacodylate buffer, and immediately after that the cells were fixed in ice cold $2.5 \%$ glutaraldehyde prepared in $0.2 \mathrm{M}$ sodium cacodylate buffer, $\mathrm{pH} 7.4$ for $4 \mathrm{~h}$ at room temperature. The pellets were then washed with cacodylate buffer, dehydrated in acetone and embedded in SPURR (Spurr's Epoxy Embedding Medium). Ultrathin sections $(70 \mathrm{~nm})$ of these samples were obtained and they were stained with uranyl acetate and lead citrate for observation under a JEOL JEM $1010(80 \mathrm{kV})$ TEM.

Control of phenotypic stability. The vaccine strains Ab $\Delta m u r I 1 \Delta m u r I 2$ and $\mathrm{Pa}$ $\Delta m u r I$ were cultured overnight at $37^{\circ} \mathrm{C}$ in $5 \mathrm{ml} \mathrm{LB}$ supplemented with $10 \mathrm{mM}$ D-Glu. Sa $\Delta$ murI $\Delta$ dat was grown overnight at $37^{\circ} \mathrm{C}$ in $5 \mathrm{ml}$ TSB supplemented with $20 \mathrm{mM}$ D-Glu. After incubation, $1 \mathrm{ml}$ of each was used to inoculate $100 \mathrm{ml}$ of LB or TSB with 10 or $20 \mathrm{mM}$ D-Glu, respectively. All the cultures were incubated at $37^{\circ} \mathrm{C}$ under agitation (180-210 r.p.m.) for up to 8 days. Samples from these cultures were taken at the beginning of the incubation period and at days $1,2,3,4$ and 8 , washed twice and plated on LB or TSB agar with 0 and $10 \mathrm{mM} \mathrm{D-Glu.} \mathrm{Agar}$ plates were incubated at $37^{\circ} \mathrm{C}$ for 4 days. Cultures were made in triplicate.

Water osmolysis assay. To determine the viability of $\mathrm{Ab}, \mathrm{Ab} \Delta$ murI1 $\Delta$ murI2, $\mathrm{Pa}, \mathrm{Pa} \Delta m u r I, \mathrm{Sa}$ and $\mathrm{Sa} \Delta m u r I \Delta d a t$ in water, these bacterial strains were cultured overnight at $37^{\circ} \mathrm{C}$ in LB or TSB agar with (mutant strains) and without (wild-type strains) $10 \mathrm{mM}$ D-Glu, adjusted to $0.5 \mathrm{McF}$ arland in water and left incubating at $37^{\circ} \mathrm{C}$ under agitation (180 r.p.m.) for the time necessary to observe the loss of viability of cells. For A. baumannii strains, daily samples of culture were taken until day 2, next samples were taken twice a week until day 26 and thereafter, once a week until day 40 for the determination of CFU counts in LB agar (wild-type strain) and LB agar with $10 \mathrm{mM}$ D-Glu (Ab $\Delta$ murI1 $\Delta$ murI2 mutant strain). For $P$. aeruginosa strains, daily samples of culture were taken until day 3 , next samples were taken twice a week until day 48 . Finally, samples were taken at least once every 2 weeks until day 157 for the determination of CFU counts in LB agar (wildtype strain) and LB agar supplemented with $10 \mathrm{mM}$ D-Glu (Pa $\Delta m u r I$ mutant strain). For $S$. aureus, daily samples of culture were taken until day 5 for the determination of CFU counts in TSB agar (wild-type strain) and TSB agar supplemented with $10 \mathrm{mM}$ D-Glu (Sa $\Delta$ murI $\Delta$ dat mutant strain). Cultures were made in triplicate.

Desiccation assay. To determine the viability of Sa and Sa $\Delta m u r I \Delta d a t$ after being kept under drought stress, these bacterial strains were cultured at $37^{\circ} \mathrm{C}$ under agitation (210 r.p.m.) in TSB and TSB with $20 \mathrm{mM}$ D-Glu, respectively. Log-phase cultures $\left(\mathrm{OD}_{600}=0.5-0.6\right)$ were centrifuged $(3,900 \mathrm{~g}, 20 \mathrm{~min})$, washed once and serially diluted in TSB. Drops of $5 \mu \mathrm{l}$ from undiluted, $10^{-1}$ - and $10^{-2}$-diluted cultures were then spotted on sterile cellulose filters $(0.45 \mu \mathrm{m}$ pore size $)$ and sequentially placed on TSB agar with D-Glu $10 \mathrm{mM}$ at day 0 (control) and after keeping for 4, 5, 6, 11, 18, 25 and 31 days at room temperature (desiccation stress). Agar plates were incubated at $37^{\circ} \mathrm{C}$ for $16 \mathrm{~h}$. All cultures were made in triplicate.

Animal experiments. All mice were maintained in the specific pathogen-free facility at the Centro Tecnológico de Formación de la Xerencia de Xestión Integrada A Coruña (CTF-XXIAC), Servicio Galego de Saúde. All experiments were done with the approval of and in accordance with regulatory guidelines and standards set by the Comité Ético de Experimentación Animal of CHUAC (Complejo Hospitalario Universitario A Coruña). Male and female mice were used for first time procedures between the ages of 6 and 8 weeks. BALB/c mice were bred in our colony and used for all experiments, unless noted. C57BL/6 mice were purchased from Harlan Sprague Dawley Inc. Blood samples were collected from the submandibular vein of anesthetized mice, and sera were separated from the blood cells by centrifugation $(1,500 \mathrm{~g}, 15 \mathrm{~min})$ and stored at $-80^{\circ} \mathrm{C}$ until subsequent analysis. To assess bacterial burden in tissues, vaccinated and control mice were euthanized at indicated time points for each experiment, tissues were extracted aseptically, homogenized in sterile $\mathrm{NaCl} 0.9 \%$ and $\mathrm{CFU}$ enumerated by plating $10^{-2}$-fold serial dilutions in agar plates. Studies were not blinded. To prepare inocula for active immunizations and infections, bacteria were cultured at $37^{\circ} \mathrm{C}$ under agitation (180-210 r.p.m.) until reaching $\mathrm{OD}_{600 \mathrm{~nm}}=0.7$. The cultures were harvested by centrifugation, pellets washed twice, suspended and adjusted in sterile $\mathrm{NaCl} 0.9 \%$ to different doses (note that vaccine vehicle was always $\mathrm{NaCl}$ $0.9 \%$ - saline). Prior to mice inoculation, bacterial inocula were quantified by CFU enumeration in agar plates. To prepare formalin-inactivated $P$. aeruginosa PAO1 and $S$. aureus 132 cultures were harvested by centrifugation, washed with saline and inactivated in $1 \%(\mathrm{w} / \mathrm{v})$ paraformaldehyde in PBS by incubation at $37^{\circ} \mathrm{C}$ under agitation (180 r.p.m.) for $2 \mathrm{~h}$. The bacteria were then washed twice with $\mathrm{NaCl} 0.9 \%$ and adjusted as before. To prepare heat-killed P. aeruginosa PAO1 and S. aureus 132 , bacteria were cultured, washed and adjust in saline as before, and then killed by incubation at $100{ }^{\circ} \mathrm{C}$ for $2 \mathrm{~h}$. Killing of bacteria was checked by plating on LB or TSB agar to determine the absence of colonies after overnight incubation. In detail, $\mathrm{Ab}, \mathrm{Ab} \Delta$ murI1 $\Delta$ murI2 ( $\alpha$-Ab vaccine), $\mathrm{Pa}$ and $\mathrm{Pa} \Delta m u r I$ ( $\alpha$-Pa vaccine) were cultured in LB with $10 \mathrm{mM}$ D-Glu (D-Glu auxotrophic strains) and LB (remaining strains) at $37^{\circ} \mathrm{C}$ and 180 r.p.m., harvested (4,000 g, $15 \mathrm{~min}$ ), washed twice with $\mathrm{LB}$ and finally adjusted with saline as above. For IP and intramuscular injections of $A$ baumannii and $P$. aeruginosa strains, we used a total volume of 100 and $50 \mu$, respectively. For intranasal inoculation of $\alpha$-Pa vaccine, we used a total volume of $20 \mu \mathrm{l}$. For P. aeruginosa PA28562 infection, bacterial pellet was suspended in $\mathrm{NaCl}$ $0.9 \%$ containing $3 \%$ of mucin from porcine stomach, type II. Mucin stock solution was solubilized in PBS at $6 \% \mathrm{w} / \mathrm{v}$, sterilized by autoclaving for $10 \mathrm{~min}$ and rapidly 
cooled in ice. Exceptionally for P. aeruginosa PA28562, we used a $250 \mu$ l volume for infection. All challenges were made using the IP route of administration. To prepare inocula of Sa and Sa $\Delta m u r I \Delta d a t$ ( $\alpha$-Sa vaccine) these strains were grown in TSB or TSB with $20 \mathrm{mM}$ D-Glu at $37^{\circ} \mathrm{C}$ and 210 r.p.m. until $\mathrm{OD}_{600 \mathrm{~nm}}=0.7$. Bacterial cultures were then centrifuged $(3,900 \mathrm{~g}, 20 \mathrm{~min})$, washed twice with sterile $\mathrm{NaCl} 0.9 \%$ and suspended in the same solution. For S. aureus infections, we prepared inocula with $3 \%$ of mucin (as described above). Both for immunizations and infections, mice were administered using the IP route with a total volume of $250 \mu \mathrm{l}$ and, unless otherwise stated, monitored for morbidity and mortality for 14 days after injections. When pertinent, mice challenged with S. aureus were weighed daily. For active immunization assays, mice were administrated one, two or three injections, depending on the schedule, of D-Glu auxotrophic strains $\alpha$-Ab, $\alpha$-Pa or $\alpha$-Sa (in saline); or Pa or Sa wild-type strains (in saline) after formalin-inactivated or heat-killed protocols. Control mice were administrated saline on parallel. Mice were challenged with bacterial strains 1-2 weeks (days 21-28, two immunizations; day 35 , three immunizations) or one and three months (days $42-43$ and 98) after the last vaccine administration. To generate naive and anti-A. baumannii serum $(\alpha-\mathrm{Ab}$ serum $)$ to be used in passive immunizations before challenging mice with $\mathrm{Ab}, \mathrm{BALB} / \mathrm{c}$ mice $(n=6 /$ group) were administered three IP injections of $\alpha$-Ab vaccine $\left(6 \times 10^{7} \mathrm{CFU}\right)$, or saline, at a 14-day interval. Blood was collected on days 36,40 and 42 ; serum was pooled and titres of total IgG were determined by indirect ELISA. IP adoptive transfer of either $250 \mu \mathrm{l} \alpha$-Ab serum $(1: 163,840)$ or naive serum (1:40) was made in naive mice ( $n=8 /$ group) $3.5 \mathrm{~h}$ before the challenge. To generate naive and $\alpha-\mathrm{Ab}$ serum to be used in passive immunizations before challenging mice with A. baumannii AbH12O-A2, BALB/c mice ( $n=6 /$ group) were administered four IP injections of $\alpha$-Ab vaccine $\left(6 \times 10^{7} \mathrm{CFU}\right)$, or saline, on days $0,14,28$ and 110. Blood was collected on day 117. IP adoptive transfer of either $200 \mu \mathrm{l} \alpha-\mathrm{Ab}$ serum or naive serum was made in naive mice ( $n=8 /$ group) $4 \mathrm{~h}$ prior to the challenge. To generate naive and anti-P. aeruginos $a$ serum ( $\alpha$-Pa serum) to be used in passive immunizations before challenging mice with $\mathrm{Pa}, \mathrm{BALB} / \mathrm{c}$ mice $(n=5 /$ group) were administered two IP injections of $\alpha$-Pa vaccine $\left(2 \times 10^{7} \mathrm{CFU}\right)$, or saline, at a 12-day interval. Blood was collected on day 19; serum was pooled and IP adoptive transfer of either $200 \mu \mathrm{l} \alpha$-Pa serum or naive serum was made in naive mice ( $n=8 /$ group) $3.5 \mathrm{~h}$ before the challenge. To generate naive and $\alpha$-Pa serum to be used in passive immunizations before challenging mice with $P$. aeruginosa PA14, BALB/c mice ( $n=8 /$ group) were administered three IP injections of $\alpha-\mathrm{Pa}$ vaccine $\left(2 \times 10^{7} \mathrm{CFU}\right)$, or saline, at a 14-day interval. Blood was collected on day 67 ; serum was pooled and titres of total IgG were determined by indirect ELISA. IP adoptive transfer of either $200 \mu \mathrm{l} \alpha$-Pa serum $(1: 81,920)$ or naive serum $(1: 160)$ was made in naive mice ( $n=8$ /group) $3.5 \mathrm{~h}$ before the challenge. To generate naive and anti-S. aureus serum ( $\alpha$-Sa serum) to be used in passive immunization before challenging mice with $S$. aureus 132, FPR3757 and NEWMAN, BALB/c mice ( $n=8$ /group) were administered six IP injections $(250 \mu \mathrm{l})$ of $\alpha$-Sa vaccine $\left(2 \times 10^{8}\right.$ $\mathrm{CFU}$ ), or saline, at a 14-day interval (days $0,14,28,42,56$ and 70 ). Blood was collected on days 49,63 and 84; sera obtained was pooled as before and IP adoptive transfer of either $200 \mu \mathrm{l} \alpha$-Sa serum $(1: 81,920)$ or naive serum (1:120) was made in naive mice ( $n=6-7 /$ group) $3.5 \mathrm{~h}$ before challenge with S. aureus 132, FPR3757 and NEWMAN strains, respectively. For intravenously injections, a total volume of $100 \mu \mathrm{l}$ of $\mathrm{Ab}$ and $\alpha-\mathrm{Ab}$ vaccine $\left(6 \times 10^{7} \mathrm{CFU}\right), \mathrm{Pa}$ and $\alpha$-Pa vaccine $\left(2 \times 10^{7} \mathrm{CFU}\right)$, and $\mathrm{Sa}\left(1.5 \times 10^{7} \mathrm{CFU}\right)$ and $\alpha$-Sa vaccine $\left(2 \times 10^{7} \mathrm{CFU}\right)$ was administered via lateral tail veins.

Indirect ELISA. Quantification of IgM, IgG, IgG1, IgG2a, IgG2b and IgG3 in mouse sera was performed using an indirect ELISA. In total, 96-well ELISA plates were 'coated' with A. baumannii, $P$. aeruginosa and S. aureus strains, which were fixed to the bottom of the wells after overnight incubation at $4^{\circ} \mathrm{C}$ in $100 \mathrm{mM}$ carbonate-bicarbonate buffer, $\mathrm{pH}$ 9.6. For the detection of specific antibodies against $\mathrm{Sa}$, a derived mutant strain deficient for the protein A (S. aureus 132 $\Delta s p a$ (ref. 29)) was used to avoid nonspecific binding between protein A and IgG or IgM antibodies. After coating, plates were washed five times with phosphate buffered saline (PBS) to remove any unfixed bacteria. The residual sites were blocked with $200 \mu \mathrm{l}$ per well of blocking solution (5\% skim milk in PBS) for $2 \mathrm{~h}$ at room temperature. An additional blocking step was used with $200 \mu \mathrm{l}$ of rabbit serum diluted 1:1,000 in PBS for $1 \mathrm{~h}$ at $37^{\circ} \mathrm{C}$ to block protein A cell surface receptors, for those $S$. aureus strains whose derived $\Delta$ spa mutants were not available. Plates were aspirated and washed 5 times with washing buffer ( $0.005 \%$ Tween 20 in PBS) and incubated overnight at $4{ }^{\circ} \mathrm{C}$ with mouse sera serially diluted in DMEM culture medium supplemented with $10 \%$ fetal bovine serum (FBS) (Gibco by Thermo Fisher Scientific, Madrid, Spain). After incubation, plates were washed five times with washing buffer to remove unbound antibodies and $100 \mu \mathrm{l}$ of secondary antibody (peroxidase-labelled anti-mouse IgM, IgG, IgG1, IgG2a, IgG2b or IgG3; or peroxidase-labelled anti-rat IgG) diluted 1:5,000 in DMEM culture medium supplemented with $10 \%$ FBS was added to each well and left incubating for $2 \mathrm{~h}$ in the dark. Plates were washed five times with washing buffer to remove any unbound secondary antibodies. Then, $100 \mu \mathrm{l}$ of $3,3^{\prime} 5,5^{\prime}-$ Tetramethylbenzidine was added to each well. The reaction was stopped after 2-3 min with $50 \mu \mathrm{l}$ of $1 \mathrm{M} \mathrm{H}_{2} \mathrm{SO}_{4}$ per well, and the peroxidase reaction product was read at $450 \mathrm{~nm}$. For end point assays, the end point titre was defined as the maximum dilution having a value that exceeded the blank absorbance reading by 0.1 values.
ELISpot assay. IFN- $\gamma$, IL-4 and IL-17-producing splenocytes were quantified by ELISpot analysis (R\&D Systems, Minneapolis, Minnesota) with splenocytes obtained from immunized $(n=6)$ and control $(n=6-7)$ mice, and exposed ex vivo to $\alpha$ - $\mathrm{Ab}\left(4 \times 10^{5} \mathrm{CFU}\right), \alpha-\mathrm{Pa}\left(8 \times 10^{4} \mathrm{CFU}\right)$ and $\alpha$-Sa $\left(3 \times 10^{6} \mathrm{CFU}\right)$ vaccines during $43 \mathrm{~h}$ at $37^{\circ} \mathrm{C}, 5 \% \mathrm{CO}_{2}$. Mice spleens were aseptically removed after the second vaccine or saline administration, mechanically disrupted and washed in saline by centrifugation at $400 \mathrm{~g}$ for $10 \mathrm{~min}$ at room temperature. The suspension of spleen cells was enriched in lymphocytes using the Histopaque solution, counted in a Neubauer haemocytometer and adjusted to $4 \times 10^{6}$ or $8 \times 10^{6} \mathrm{cells} \mathrm{ml}^{-1}$ in RPMI 1640 medium containing $10 \%$ FBS. Next, $100 \mu$ l were transferred to a 96well EliSpot plates and restimulated with $100 \mu \mathrm{l}$ of vaccine strain, $100 \mu \mathrm{l}$ of $1 \times$ cell stimulation cocktail (positive control) or $100 \mu \mathrm{l}$ RPMI $+10 \%$ FBS. The number of the spot-forming units was visually determined using images obtained with a dissecting microscope (Nikon SMZ-745, Nikon Corporation). Spot frequency in stimulated wells was corrected by subtracting background signal from wells with cells plus media alone.

Opsonophagocytic and killing assays. OPKA were assessed against $A$. baumannii and P. aeruginosa, whereas OPA activity was determined for $S$. aureus using $\alpha-\mathrm{Ab}, \alpha-\mathrm{Pa}$ and $\alpha$-Sa sera (or naive serum), respectively. In brief, RAW 264.7 murine cells (ATCC TIB-71) were used as phagocytic cells for A. baumannii and $S$. aureus assays and maintained at low passages in DMEM supplemented with $10 \%$ FBS and $2 \%$ penicillin-streptomycin in a $5 \% \mathrm{CO}_{2}$ atmosphere at $37^{\circ} \mathrm{C}$. Murine macrophages were activated by 3 -day exposition to $100 \mathrm{nM}$ of phorbol 12 -myristate 13-acetate (PMA, Sigma-Aldrich) in DMEM plus 10\% FBS, harvested after scraping (Cell scraper 179693, Nalgene Nunc International), counted in a Neubauer haemocytometer and adjusted in the same medium to $2 \times 10^{6}$ cells ml ${ }^{-1}$ Reactions were conducted in 96-well cell culture plates (Costar 3596, Corning Inc.) at $37^{\circ} \mathrm{C}-5 \% \mathrm{CO}_{2}$. A final volume of $100 \mu \mathrm{l}$ was added to each well: $80 \mu \mathrm{l}$ of RAW cells, $10 \mu \mathrm{l}$ mouse serum (vaccine or naive) and $10 \mu \mathrm{l}$ of bacteria. We tested $\alpha$-Ab serum (1:100 final dilution) (or naive serum) to measure OPKA against $\mathrm{A}$. baumannii ATCC 17978, ATCC 19606, AbH12O-A2 and Ab307-0294 strains. OPKA against Ab307-0294 consisted of the target strain, RAW cells, mouse serum and $2.5 \%$ complement serum from rabbit (Sigma-Aldrich). Bacteria were cultured in LB at $37^{\circ} \mathrm{C}$ until $\mathrm{OD}_{600 \mathrm{~nm}}$ of 0.7 , washed twice in saline, adjusted in DMEM $+10 \%$ FBS and added to the wells at the indicated CFU. After $2.5 \mathrm{~h}$ incubation at $37^{\circ} \mathrm{C}$, the reaction mixtures-RAW cells plus mouse sera and bacteria-were aspirated, diluted and plated in duplicate onto LB plates for CFU determination to calculate the killing activity. $\alpha$-Sa serum (1:10 final dilution) (or naive serum) was tested to measure OPA against S. aureus 132, FRP3757, MW2, NEWMAN, Sa07997, ED133 and ED98 strains. Bacteria were cultured in TSB at $37^{\circ} \mathrm{C}$ until $\mathrm{OD}_{600 \mathrm{~nm}}$ of 0.7 , washed twice in saline, adjusted in DMEM $+10 \%$ FBS and added to the wells at the indicated CFU. After 1 hour incubation at $37^{\circ} \mathrm{C}$, supernatants were aspirated (mouse sera and bacteria), diluted and plated in duplicate onto TSA plates for CFU determination to calculate the opsonophagocytosis activity. OPKA against $P$. aeruginosa consisted of the target strain, $5 \times 10^{6}$ polymorphonuclear leukocytes (PMNs) from human volunteers, $2.5 \%$ complement serum from rabbit and test sera (1:2 final dilution), all prepared in RPMI 1640 medium containing 10\% FBS. After $2.5 \mathrm{~h}$ incubation at $37^{\circ} \mathrm{C}$ with slight agitation, the reaction mixtures-PMNs cells plus mouse sera and bacteria-were aspirated, diluted and plated in duplicate onto LB plates for CFU determination to calculate the killing activity. Each sample was tested in quintuplicate. Per cent of opsonophagocytosis or killing was calculated as 100-((CFU from individual well/average CFU in naive serum control wells) $\times 100)$.

Statistics. Means were compared by using Student's $t$-test for hypothesis testing to compare individual conditions and corresponding control groups. Mann-Whitney $U$-test was applied if data set failed the Kolmogorov-Smirnov normality test. The one-way analysis of variance (ANOVA) was used for multiple comparisons, followed by Bonferroni's post hoc test. Survival data were compared using the log-rank test. Differences were considered significant when $P<0.05$. ${ }^{*} P<0.05$ compared with control group. $\# P<0.05$ compared with the preceding group represented. All statistical analyses were performed using Prism 6.0 (GraphPad Prism, GraphPad Software, Inc.).

Data availability. The authors declare that all the relevant data supporting the findings of the study are available in the article and its Supplementary Information files, or from the corresponding author upon request.

\section{References}

1. Boucher, H. W. et al. Bad bugs, no drugs: no ESKAPE! An update from the Infectious Diseases Society of America. Clin. Infect. Dis. 48, 1-12 (2009).

2. Fowler, Jr V. G. \& Proctor, R. A. Where does a Staphylococcus aureus vaccine stand? Clin. Microbiol. Infect. 20(Suppl 5): 66-75 (2014).

3. Priebe, G. \& Goldberg, J. Vaccines for Pseudomonas aeruginosa: a long and winding road. Expert Rev. Vaccines 13, 507-519 (2014). 
4. Dayan, G. et al. Staphylococcus aureus: The current state of disease, pathophysiology and strategies for prevention. Expert Rev. Vaccines 9, 1-20 (2016).

5. Knisely, J. M., Liu, B., Ranallo, R. T. \& Zou, L. Vaccines for healthcareassociated infections: promise and challenge. Clin. Infect. Dis. 63, 657-662 (2016).

6. Huang, W. et al. Immunization with a $22-\mathrm{kDa}$ outer membrane protein elicits protective immunity to multidrug-resistant Acinetobacter baumannii. Sci. Rep. 6, 20724 (2016).

7. Li, Y. et al. X-ray irradiated vaccine confers protection against pneumonia caused by Pseudomonas aeruginosa. Sci. Rep. 6, 18823 (2016).

8. Yang, L. et al. Protective efficacy of the chimeric Staphylococcus aureus vaccine candidate IC in sepsis and pneumonia models. Sci. Rep. 6, 20929 (2016).

9. The National Vaccine Advisory Committee. A call for greater consideration for the role of vaccines in national strategies to combat antibiotic-resistant bacteria: recommendations from the national vaccine advisory committee. Public Health Rep. 131, 11-17 (2016).

10. Levine, M. M. et al. Safety, immunogenicity, and efficacy of recombinant live oral cholera vaccines, CVD 103 and CVD 103-HgR. Lancet 2, 467-470 (1988).

11. Simanjuntak, C. H. et al. Oral immunisation against typhoid fever in Indonesia with Ty21a vaccine. Lancet 338, 1055-1059 (1991).

12. Liu, J., Tran, V., Leung, A. S., Alexander, D. C. \& Zhu, B. BCG vaccines: their mechanisms of attenuation and impact on safety and protective efficacy. Hum. Vaccin 5, 70-78 (2009).

13. Michael, A., Geier, E., Konshtok, R., Hertman, I. \& Markenson, J. Attenutated live fowl cholera vaccine. III. Laboratory and field vaccination trials in turkeys and chickens. Avian Dis. 23, 878-885 (1979).

14. Panciera, R. J., Corstvet, R. E., Confer, A. W. \& Gresham, C. N. Bovine pneumonic pasteurellosis: effect of vaccination with live Pasteurella species. Am. J. Vet. Res. 45, 2538-2542 (1984).

15. Sakano, T., Sakurai, K., Furutani, T. \& Shimizu, T. Immunogenicity and safety of an attenuated Bordetella bronchiseptica vaccine in pigs. Am. J. Vet. Res. 45, 1814-1817 (1984).

16. Turnbull, P. C. B. Review Anthrax vaccines: past, present and future. Vaccine 9 , 533-539 (1991).

17. Thiaucourt, F. et al. Contagious bovine pleuropneumonia. A reassessment of the efficacy of vaccines used in Africa. Ann. N Y Acad. Sci. 916, 71-80 (2000).

18. Schurig, G. G., Sriranganathan, N. \& Corbel, M. J. Brucellosis vaccines: past, present and future. Vet. Microbiol. 90, 479-496 (2002).

19. Begg, D. J. \& Griffin, J. F. Vaccination of sheep against M. paratuberculosis: immune parameters and protective efficacy. Vaccine 23, 4999-5008 (2005).

20. Lee, Y. J., Mo, I. P. \& Kang, M. S. Safety and efficacy of Salmonella gallinarum 9R vaccine in young laying chickens. Avian Pathol. 34, 362-366 (2005).

21. van Heijenoort, J. Formation of the glycan chains in the synthesis of bacterial peptidoglycan. Glycobiology 11, 25R-36R (2001).

22. Schleifer, K. H. \& Kandler, O. Peptidoglycan types of bacterial cell walls and their taxonomic implications. Bacteriol. Rev. 36, 407-477 (1972).

23. Tomasz, A. in Gram-positive pathogens (eds Fischetti, V. et al.) $443-455$ (ASM, 2006).

24. Vollmer, W., Blanot, D. \& de Pedro, M. A. Peptidoglycan structure and architecture. FEMS Microbiol. Rev. 32, 149-167 (2008).

25. Fisher, S. L. Glutamate racemase as a target for drug discovery. Microb. Biotechnol. 1, 345-360 (2008).

26. Oh, S. Y., Richter, S. G., Missiakas, D. M. \& Schneewind, O. Glutamate racemase mutants of Bacillus anthracis. J. Bacteriol. 197, 1854-1861 (2015).

27. Smith, M. G. et al. New insights into Acinetobacter baumannii pathogenesis revealed by high-density pyrosequencing and transposon mutagenesis. Genes Dev. 21, 601-614 (2007).

28. Stover, C. K. et al. Complete genome sequence of Pseudomonas aeruginosa PAO1, an opportunistic pathogen. Nature 406, 959-964 (2000).

29. Vergara-Irigaray, M. et al. Relevant role of fibronectin-binding proteins in Staphylococcus aureus biofilm-associated foreign-body infections. Infect. Immun. 77, 3978-3991 (2009).

30. Frey, J. Biological safety concepts of genetically modified live bacterial vaccines. Vaccine 25, 5598-5605 (2007).

31. Mills, C. D., Kincaid, K., Alt, J. M., Heilman, M. J. \& Hill, A. M. M-1/M-2 macrophages and the Th1/Th2 paradigm. J. Immunol. 164, 6166-6173 (2000).

32. Pritt, B., O'Brien, L. \& Winn, W. Mucoid Pseudomonas in cystic fibrosis. Am. J. Clin. Pathol. 128, 32-34 (2007).

33. Curtiss, 3rd R. Bacterial infectious disease control by vaccine development. J. Clin. Invest. 110, 1061-1066 (2002).

34. Miyoshi, Y., Oyama, T., Itoh, Y. \& Hamase, K. Enantioselective twodimensional high-performance liquid chromatographic determination of amino acids; analysis and physiological significance of D-amino acids in mammals. J. Chromatogr. A 35, 49-57 (2014).

35. O’Callaghan, D., Maskell, D., Liew, F. Y., Easmon, C. S. F. \& Dougan, G. Characterization of aromatic- and purine-dependent Salmonella typhimurium: attenuation, persistence, and ability to induce protective immunity in BALB/c mice. Infect. Immun. 56, 419-423 (1988).

36. Jackson, M. et al. Persistence and protective efficacy of a Mycobacterium tuberculosis auxotroph vaccine. Infect. Immun. 67, 2867-2873 (1999).

37. Priebe, G. P. et al. Construction and characterization of a live, attenuated aroA deletion mutant of Pseudomonas aeruginosa as a candidate intranasal vaccine. Infect. Immun. 70, 1507-1517 (2002).

38. Buzzola, F. R., Barbagelata, M. S., Caccuri, R. L. \& Sordelli, D. O. Attenuation and persistence of and ability to induce protective immunity to a Staphylococcus aureus aroA mutant in mice. Infect. Immun. 74, 3498-3506 (2006).

39. Priebe, G. P. et al. IL-17 is a critical component of vaccine-induced protection against lung infection by lipopolysaccharide-heterologous strains of Pseudomonas aeruginosa. J. Immunol. 181, 4965-4975 (2008).

40. Kamei, A., Coutinho-Sledge, Y. S., Goldberg, J. B., Priebe, G. P. \& Pier, G. B. Mucosal vaccination with a multivalent, live-attenuated vaccine induces multifactorial immunity against Pseudomonas aeruginosa acute lung infection. Infect. Immun. 79, 1289-1299 (2011).

41. Lin, M. F. \& Lan, C. Y. Antimicrobial resistance in Acinetobacter baumannii: From bench to bedside. World J. Clin. Cases 2, 787-814 (2014).

42. Pachón, J. \& McConnell, M. J. Considerations for the development of a prophylactic vaccine for Acinetobacter baumannii. Vaccine 32, 2534-2536 (2014).

43. Perez, F. \& Bonomo, R. Vaccines for Acinetobacter baumannii: Thinking 'out of the box'. Vaccine 32, 2537-2539 (2014).

44. García-Quintanilla, M., Pulido, M. R., Pachón, J. \& McConnell, M. J. Immunization with lipopolysaccharide-deficient whole cells provides protective immunity in an experimental mouse model of Acinetobacter baumannii Infection. PLoS ONE 9, e114410 (2014).

45. Sharma, A., Krause, A. \& Worgall, S. Recent developments for Pseudomonas vaccines. Hum. Vaccin. 7, 999-1011 (2011).

46. Grimwood, K., Kyd, J. M., Owen, S. J., Massa, H. M. \& Cripps, A. W. Vaccination against respiratory Pseudomonas aeruginosa infection. Hum. Vaccin. Immunother. 11, 14-20 (2015).

47. Priebe, G. P., Meluleni, G. J., Coleman, F. T., Goldberg, J. B. \& Pier, G. B. Protection against fatal Pseudomonas aeruginosa pneumonia in mice after nasal immunization with a live, attenuated aroA deletion mutant. Infect. Immun. 71, 1453-1461 (2003).

48. Dunkley, M. L., Cripps, A. W., Reinbott, P. W. \& Clancy, R. L. Immunity to respiratory Pseudomonas aeruginosa infection: the role of gut-derived T helper cells and immune serum. Adv. Exp. Med. Biol. 371B, 771-775 (1995).

49. Jain-Vora, S. et al. Interleukin-4 enhances pulmonary clearance of Pseudomonas aeruginosa. Infect. Immun. 66, 4229-4236 (1998).

50 . Liu, J. et al. Early production of IL-17 protects against acute pulmonary Pseudomonas aeruginosa infection in mice. FEMS Immunol. Med. Microbiol. 61, 179-188 (2011).

51. Scully, I. L., Liberator, P. A., Jansen, K. U. \& Anderson, A. S. Covering all the bases: preclinical development of an effective Staphylococcus aureus vaccine. Front. Immunol. 5, 109 (2014).

52. Proctor, R. A. Recent developments for Staphylococcus aureus vaccines: clinical and basic science challenges. Eur. Cell Mater. 30, 315-326 (2015).

53. Giersing, B. K., Dastgheyb, S. S., Modjarrad, K. \& Moorthy, V. Status of vaccine research and development of vaccines for Staphylococcus aureus. Vaccine 34, 2962-2966 (2016).

54. Missiakas, D. \& Schneewind, O. Staphylococcus aureus vaccines: deviating from the carol. J. Exp. Med. 213, 1645-1653 (2016).

55. Middleton, J. R. Staphylococcus aureus antigens and challenges in vaccine development. Expert Rev. Vaccines 7, 805-815 (2008).

56. Bagnoli, F., Bertholet, B. \& Grandi, G. Inferring reasons for the failure of Staphylococcus aureus. Front. Cell Infect. Microbiol. 2, 16 (2012).

57. Proctor, R. A. Challenges for a universal Staphylococcus aureus vaccine. Clin. Infect. Dis. 54, 1179-1186 (2012).

58. Bothelho-Nevers, E. et al. Staphylococcal vaccine development: review of past failures and plea for future evaluation of vaccine efficacy not only on staphylococcal infections but also on mucosal carriage. Expert Rev. Vaccines $\mathbf{1 2}$, 1249-1259 (2013).

59. Ahman, A. \& Skinner, G. R. B. Inactivated staphylococcal whole-cell vaccine. PCT/GB2007/002792. Vaccine Research International PLC (2007). https:// patents.google.com/patent/WO2009013443A1/en.

60. Zhao, Y. X., Nilsson, I. M. \& Tarkowski, A. The dual role of interferon-gamma in experimental Staphylococcus aureus septicaemia versus arthritis. Immunology 93, 80-85 (1998).

61. Brown, A. F. et al. Memory Th1 cells are protective in invasive Staphylococcus aureus infection. PLoS Pathog. 11, e1005226 (2015).

62. Iwakura, Y., Nakae, S., Saijo, S. \& Ishigame, H. The roles of IL-17A in inflammatory immune responses and host defense against pathogens. Immunol. Rev. 226, 57-79 (2008). 
63. Spellberg, B. et al. The antifungal vaccine derived from the recombinant $\mathrm{N}$ terminus of Als3p protects mice against the bacterium Staphylococcus aureus. Infect. Immun. 76, 4574-4580 (2008).

64. Lin, L. et al. Th1-Th17 cells mediate protective adaptive immunity against Staphylococcus aureus and Candida albicans infection in mice. PLoS Pathog. 5, e1000703 (2009).

65. Joshi, A. et al. Immunization with Staphylococcus aureus iron regulated surface determinant B (IsdB) confers protection via Th17/IL17 pathway in a murine sepsis model. Hum. Vaccin. Immunother. 8, 336-346 (2012).

66. Hamad, M. A., Zajdowicz, S. L., Holmes, R. K. \& Voskuil, M. I. An allelic exchange system for compliant genetic manipulation of the select agents Burkholderia pseudomallei and Burkholderia mallei. Gene 430, 123-131 (2009).

67. Hoang, T. T., Karkhoff-Schweizer, R. R., Kutchma, A. J. \& Schweizer, H. P. A broad-host-range Flp-FRT recombination system for site-specific excision of chromosomally-located DNA sequences: application for isolation of unmarked Pseudomonas aeruginosa mutants. Gene 212, 77-86 (1998).

68. Arnaud, M., Chastanet, A. \& Debarbouille, M. New vector for efficient allelic replacement in naturally nontransformable, low-GC-content, gram-positive bacteria. Appl. Environ. Microbiol. 70, 6887-6891 (2004).

69. Monk, I. R., Shah, I. M., Xu, M., Tan, M. W. \& Foster, T. J. Transforming the untransformable: application of direct transformation to manipulate genetically Staphylococcus aureus and Staphylococcus epidermidis. mBio. 3, e00277-11 (2012).

\section{Acknowledgements}

This work was funded by the Projects PI12/00552 and PI15/00860, integrated in the National Plan for Scientific Research, Development and Technological Innovation 2013-2016 and funded by the Instituto de Salud Carlos III (ISCIII) and Subdirección General de Redes y Centros de Investigación Cooperativa, Ministerio de Economía, Industria y Competitividad, Spanish Network for Research in Infectious Diseases (REIPI RD12/0015/0014 and REIPI RD16/0016/0006)—co-financed by European Development Regional Fund ERDF 'A way to achieve Europe', Operative program Intelligent Growth 2014-2020. This work was also supported by the program 'Innova Saúde' implemented by SERGAS-Galician Healthcare Service. MPC was supported by a PhD scholarship (SFRH/BD/64740/2009) from Portugal and POPH/FSE. PG was supported by the Spanish Network for Research in Infectious Diseases (REIPI RD12/0015/0014 and RD16/ 0016/0006). AB was supported by the Miguel Servet Programme CP13/00226. AP was supported by the Galician Plan for Research, Innovation and Growth (I2C Plan, 2011-2015). We are grateful to S. Rodríguez and M. Fernández for technical assistance. C. Juan (Hospital Universitario Son Espases) for technical advice, B. Fernández for the provision of clinical P. aeruginosa and S. aureus strains (University Hospital A Coruña), D. Velasco and L.P. Barbeyto for the provision of clinical CoN-Staphylococci strains, T. Russo (The University at Buffalo-State University of New York) for Ab307-0294, C.
Winstanley (University of Liverpool) for LES400 and LES431, J. Blázquez (IBIS-University Hospital Virgen del Rocío)) for PA14, F. Chaves (Hospital 12 de Octubre) for PA21_ST175, C. Peña (Hospital Universitari de Bellvitge) for PA_ST235, M. Rodicio (Universidad de Oviedo) and L. Cavaco (Technical University of Denmark) for RN4220, T. Foster (Trinity College) for DH10 $\beta$, F. DeLeo (National Institute of Allergy and Infectious Diseases, USA) for FPR3757-USA300LAC and for MW2, T. Baba (Juntendo University) for NEWMAN, R. Fitzgerald (Trinity College) for RF122, ED133 and ED98, M. Voskuil (University of Colorado School of Medicine) for pMo130, H. Schweizer (Colorado State University) for pEX18Gm and I. Lasa (Instituto de AgrobiotecnologiaCSIC-Universidad Pública de Navarra) for S. aureus 132, $132 \Delta s p a$ and pMAD.

\section{Author contributions}

M.P.C., P.G., A.B. and G.B. conceived and designed the experiments. M.P.C., P.G., A.B., C.R., A.P. and M.M. performed the experiments. M.P.C., P.G. and G.B. analysed data. M.P.C., P.G. and G.B. wrote the paper. All authors read and approved the final manuscript.

\section{Additional information}

Supplementary Information accompanies this paper at http://www.nature.com/ naturecommunications

Competing interests: The authors declare no competing financial interests.

Reprints and permission information is available online at http://npg.nature.com/ reprintsandpermissions/

How to cite this article: Cabral, M. P. et al. Design of live attenuated bacterial vaccines based on D-glutamate auxotrophy. Nat. Commun. 8, 15480 doi: 10.1038/ncomms15480 (2017).

Publisher's note: Springer Nature remains neutral with regard to jurisdictional claims in published maps and institutional affiliations.

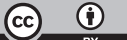

This work is licensed under a Creative Commons Attribution 4.0 International License. The images or other third party material in this article are included in the article's Creative Commons license, unless indicated otherwise in the credit line; if the material is not included under the Creative Commons license, users will need to obtain permission from the license holder to reproduce the material. To view a copy of this license, visit http://creativecommons.org/licenses/by/4.0/

(C) The Author(s) 2017 